\title{
Lignin biosynthesis perturbations affect secondary cell wall composition and saccharification yield in Arabidopsis thaliana
}

\author{
Rebecca Van Acker ${ }^{1,2}$, Ruben Vanholme ${ }^{1,2}$, Véronique Storme ${ }^{1,2}$, Jennifer C Mortimer ${ }^{3}$, Paul Dupree ${ }^{3}$
} and Wout Boerjan ${ }^{1,2^{*}}$

\begin{abstract}
Background: Second-generation biofuels are generally produced from the polysaccharides in the lignocellulosic plant biomass, mainly cellulose. However, because cellulose is embedded in a matrix of other polysaccharides and lignin, its hydrolysis into the fermentable glucose is hampered. The senesced inflorescence stems of a set of 20 Arabidopsis thaliana mutants in 10 different genes of the lignin biosynthetic pathway were analyzed for cell wall composition and saccharification yield. Saccharification models were built to elucidate which cell wall parameters played a role in cell wall recalcitrance.

Results: Although lignin is a key polymer providing the strength necessary for the plant's ability to grow upward, a reduction in lignin content down to $64 \%$ of the wild-type level in Arabidopsis was tolerated without any obvious growth penalty. In contrast to common perception, we found that a reduction in lignin was not compensated for by an increase in cellulose, but rather by an increase in matrix polysaccharides. In most lignin mutants, the saccharification yield was improved by up to $88 \%$ cellulose conversion for the cinnamoyl-coenzyme A reductase 1 mutants under pretreatment conditions, whereas the wild-type cellulose conversion only reached $18 \%$. The saccharification models and Pearson correlation matrix revealed that the lignin content was the main factor determining the saccharification yield. However, also lignin composition, matrix polysaccharide content and composition, and, especially, the xylose, galactose, and arabinose contents influenced the saccharification yield. Strikingly, cellulose content did not significantly affect saccharification yield.
\end{abstract}

Conclusions: Although the lignin content had the main effect on saccharification, also other cell wall factors could be engineered to potentially increase the cell wall processability, such as the galactose content. Our results contribute to a better understanding of the effect of lignin perturbations on plant cell wall composition and its influence on saccharification yield, and provide new potential targets for genetic improvement.

Keywords: Arabidopsis thaliana, Lignin, Cellulose, Matrix polysaccharides, Secondary cell wall, Saccharification

\section{Background}

Since the industrial revolution, mankind has exploited fossil energy sources for manufacturing and transport. Depletion of petroleum reserves, geopolitical tension, and climate change have increased the need for alternative and sustainable sources of energy [1]. One of the

\footnotetext{
*Correspondence: woboe@psb.vib-ugent.be

'Department of Plant Systems Biology, VIB, Technologiepark 927, Gent 9052, Belgium

${ }^{2}$ Department of Plant Biotechnology and Bioinformatics, Ghent University, Gent 9052, Belgium

Full list of author information is available at the end of the article
}

potential alternatives, besides solar radiation and wind, is lignocellulosic biomass of which the sugar fraction in the secondary cell wall (cellulose and hemicelluloses) can be used for the production of liquid biofuels, such as bioethanol [2]. However, the enzymatic processing of plant biomass into fermentable sugars, called saccharification, is hampered by the complexity of the secondary cell wall structure and the presence of lignin [3].

The major component of the secondary cell wall is cellulose, a polymer of 1,4-linked $\beta$-D-glucose units, of which the largest fraction is organized into microfibrils

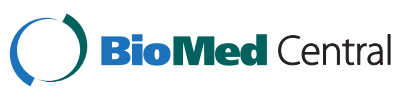


through inter- and intramolecular hydrogen bonds and van der Waals forces. The fraction of the microfibrilbound cellulose is called crystalline cellulose to distinguish it from the remaining 'unorganized' cellulose, called amorphous cellulose [4]. The spaces between individual cellulose microfibrils are largely filled with hemicelluloses that are far more complex in sugar composition and linkage types than cellulose. In angiosperms, the major hemicelluloses are glucuronoxylans, xyloglucans, and glucomannans [5]. Glucuronoxylans consist of a linear backbone of 1,4-linked $\beta$-Dxylopyranosyl units that are substituted with acetyl and 4-O-methylglucuronic acid side chains. Xyloglucans are made of a D-glucose backbone of which $75 \%$ of the residues are substituted by D-xylose. In addition, L-arabinose and D-galactose residues can be attached to the xylose residues [6]. Glucomannans occur in minor amounts in the secondary cell wall of hardwoods and are linear chains of glucose and mannose residues [5]. The third major type of polymer in the secondary cell wall is lignin. In dicotyledonous plants, lignin is mainly made from the monolignols coniferyl alcohol and sinapyl alcohol and traces of $p$-coumaryl alcohol that give rise to guaiacyl $(\mathrm{G})$, syringyl $(\mathrm{S})$, and $p$-hydroxyphenyl $(\mathrm{H})$ units. Most of these units are linked via ether bonds (in so-called
$\beta-\mathrm{O}-4$-structures) and carbon-carbon bonds [in resinol $(\beta-\beta)$, and phenylcoumaran $(\beta-5)$ structures] $[7,8]$. The monolignols are synthesized from phenylalanine through the general phenylpropanoid and monolignol-specific pathways (Figure 1). After the monolignols are transported to the cell wall, they are oxidized by laccases and peroxidases to monolignol radicals that then couple in a combinatorial fashion, finally generating the lignin polymer.

To tailor biomass for improved cell wall deconstruction, a profound knowledge is required of the factors that determine the recalcitrance of cell walls to saccharification [9]. One of the major factors causing recalcitrance to saccharification is the presence of lignin, as shown in a series of transgenic alfalfa (Medicago sativa) lines with variable lignin amount and composition [3] and, later on, in tobacco (Nicotiana tabacum) [10], maize (Zea mays) [11], switchgrass (Panicum virgatum) [12-14], sugarcane (Saccharum sp.) [15], sorghum (Sorghum bicolor) [16], brachypodium (Brachypodium distachyon) [17], poplar (Populus sp.) [18-21], and eucalyptus (Eucalyptus globulus) [22]. Besides the lignin amount, the lignin composition affects saccharification as well [19,22-24]. A few studies also pointed to the influence of cell wall polysaccharides: cellulose crystallinity $[22,25,26]$, hemicellulose amount and composition [10,26,27], and

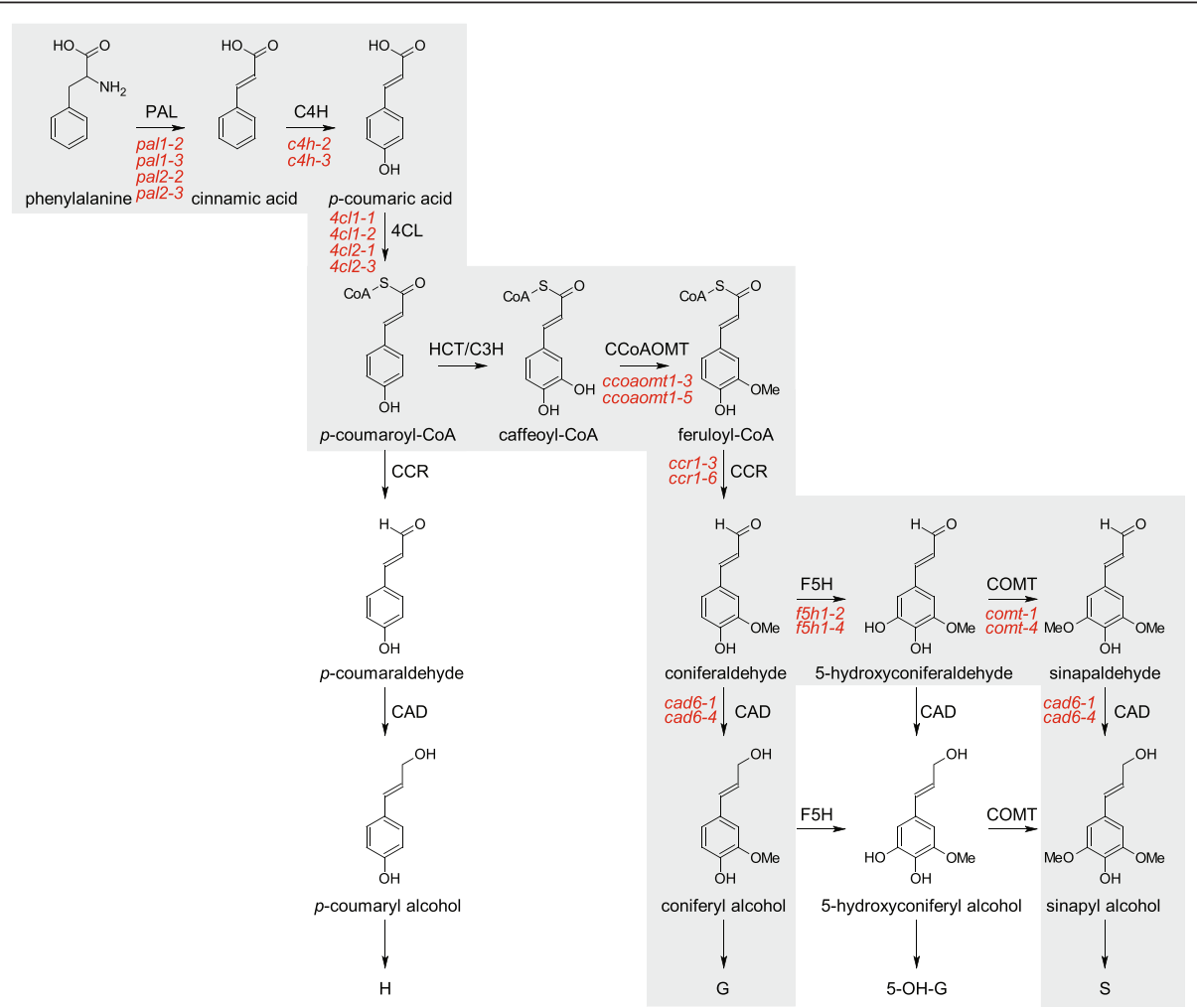

Figure 1 Phenylpropanoid and monolignol biosynthetic pathways. The grey box represents the phenylpropanoid and monolignol biosynthetic pathways that are generally accepted for angiosperms with indication of the 20 mutant alleles studied (in red). The general phenylpropanoid pathway starts with PAL and ends with CCOAOMT, whereas the monolignol-specific biosynthesis starts with CCR. 
perhaps xylan branching [28]. Cell wall engineering is complicated by our limited knowledge about potential crosstalk between the biosynthetic pathways of the main cell wall polymers. For example, several reports have suggested that a reduced lignin amount is compensated for by an increase in cellulose, as observed in poplars downregulated in 4-coumarate:CoA ligase $(4 C L)$ and caffeic acid $O$-methyltransferase (COMT) [29-31]. However, in an in-depth study of a series of lignin-deficient Arabidopsis thaliana mutants, no such correlation was found in any of these mutants [32].

To investigate whether lignin deficiency alters the level or composition of cell wall polysaccharides, we analyzed the amount and composition of the three main cell wall polymers (lignin, cellulose, and matrix polysaccharides) of the senesced inflorescence stems of Arabidopsis mutants, mutated in 10 different genes of the phenylpropanoid and monolignol biosynthetic pathways [32], i.e., two mutant alleles of each gene encoding phenylalanine ammonia lyase 1 (PAL1), PAL2, cinnamate 4-hydroxylase $(C 4 H), 4 C L 1,4 C L 2$, caffeoyl-CoA O-methyltransferase 1 (CCOAOMT1), cinnamoyl-CoA reductase 1 (CCR1), ferulate 5-hydroxylase 1 (F5H1), COMT, and cinnamyl alcohol dehydrogenase 6 (CAD6). In addition, we developed a small-scale saccharification protocol for Arabidopsis inflorescence stems and analyzed whether the altered cell wall composition in the mutants affected the saccharification yield. Analysis by whole cell wall Nuclear Magnetic Resonance (NMR) methods provided comparable findings on the lignin composition (see Chylla et al., accompanying paper). The high number of mutants and biological replicates allowed us to draw correlations among cell wall composition and saccharification yield and to design a statistical model for the saccharification yield as a function of the cell wall composition.

\section{Results}

\section{Biomass of Arabidopsis lignin mutants}

For 10 genes of the phenylpropanoid and monolignol biosynthetic pathways, two mutant alleles (pal1-2, pal13, pal2-2, pal2-3, c4h-2, c4h-3, 4cl1-1, 4cl1-2, 4cl2-1, 4cl2-3, ccoaomt1-3, ccoaomt1-5, ccr1-3, ccr1-6, f5h1-2, f5h1-4, comt-1, comt-4, cad6-1, and cad6-4 [32]) were grown in 16 biological replicates in a controlled growth room, together with 32 replicates of the wild-type. To compare the cell wall composition and saccharification yield, these mutants should ideally develop similarly as the wild-type. Because perturbations in the lignin biosynthesis often affected plant growth, we first compared the final height and weight of the senesced inflorescence stems of the mutants with those of the wild-type (Table 1). Most mutants were comparable to wild-type, with a few exceptions. As anticipated, developmental defects were noticed for $c 4 h-2, c c r 1-3$, and $c c r 1-6$, of which
Table 1 Phenotypic traits

\begin{tabular}{|c|c|c|c|}
\hline Line & Height $(\mathrm{cm})$ & Mass (mg) & $\%$ CWR \\
\hline WT Col-0 & $49.6 \pm 3.7$ & $64.3 \pm 9.9$ & $78.4 \pm 1.7$ \\
\hline pal1-2 & $49.4 \pm 3.0$ & $63.4 \pm 13.5$ & $76.6 \pm 1.9$ \\
\hline pal1-3 & $49.3 \pm 3.5$ & $57.5 \pm 10.3$ & $76.3 \pm 3.5$ \\
\hline pal2-2 & $48.8 \pm 2.4$ & $62.5 \pm 9.5$ & $77.7 \pm 1.8$ \\
\hline pal2-3 & $45.6 \pm 2.9$ & $54.6 \pm 14.4$ & $76.7 \pm 1.8$ \\
\hline$c 4 h-2$ & $35.4 \pm 4.9^{*}$ & $31.1 \pm 8.6^{*}$ & $76.6 \pm 2.3$ \\
\hline$c 4 h-3$ & $49.9 \pm 2.8$ & $55.9 \pm 12.9$ & $78.7 \pm 1.8$ \\
\hline $4 c 11-1$ & $49.2 \pm 2.0$ & $63.4 \pm 8.5$ & $79.1 \pm 2.4$ \\
\hline $4 c / 1-2$ & $49.2 \pm 2.7$ & $62.5 \pm 8.2$ & $78.3 \pm 2.3$ \\
\hline $4 c 12-1$ & $47.9 \pm 3.8$ & $59.6 \pm 13.5$ & $77.3 \pm 0.8$ \\
\hline $4 c 12-3$ & $48.2 \pm 3.9$ & $62.9 \pm 15.8$ & $77.2 \pm 3.0$ \\
\hline ccoaomt1-3 & $45.9 \pm 4.9$ & $44.5 \pm 10.2^{*}$ & $77.8 \pm 3.3$ \\
\hline ccoaomt1-5 & $45.9 \pm 2.4$ & $57.6 \pm 11.7$ & $77.1 \pm 2.5$ \\
\hline ccrl-3 & $8.6 \pm 1.9^{*}$ & $14.9 \pm 1.5^{*}$ & $67.1 \pm 4.0^{*}$ \\
\hline ccrl-6 & $32.5 \pm 2.3^{*}$ & $45.4 \pm 6.5^{*}$ & $72.6 \pm 2.9^{*}$ \\
\hline$f 5 h 1-2$ & $45.0 \pm 1.8$ & $59.3 \pm 8.6$ & $78.7 \pm 1.6$ \\
\hline$f 5 h 1-4$ & $47.1 \pm 4.2$ & $60.5 \pm 18.3$ & $78.6 \pm 2.1$ \\
\hline comt-1 & $47.4 \pm 3.1$ & $56.3 \pm 13.4$ & $76.7 \pm 1.7$ \\
\hline comt-4 & $47.4 \pm 6.7$ & $58.4 \pm 13.3$ & $77.0 \pm 2.3$ \\
\hline cad6-1 & $51.2 \pm 2.2$ & $63.1 \pm 9.6$ & $80.0 \pm 2.3$ \\
\hline cad6-4 & $46.1 \pm 2.6$ & $54.5 \pm 10.1$ & $78.2 \pm 1.7$ \\
\hline
\end{tabular}

Height and biomass were determined on fully senesced primary inflorescence stems (free of rosette leaves, axillary inflorescences, and siliques). The data represent the average value of 16 biological repeats for the mutants and 32 biological repeats for the wild-type $(W T)( \pm S D)$. The cell wall residue (CWR) (expressed as \% dry weight) was determined gravimetrically after a sequential extraction (mutants, $\mathrm{n}=8$; wild-type, $\mathrm{n}=16$ ). Decreases compared to the wild-type are in italics. ${ }^{*} p<0.001$ (Dunnett-Hsu adjusted $t$-test).

the final height of their inflorescence stems was reduced by $29 \%, 83 \%$, and $34 \%$ as compared to the wild-type, respectively [32-34]. Notably, the ccr1-3 mutant had a bushy appearance with a small primary inflorescence (that died early) and many secondary inflorescences. The strongest reduction in biomass, as measured by the weight of the primary senesced inflorescence stem (without rosette leaves, axillary inflorescences, and siliques), was seen for c4h-2, ccr1-3, and ccr1-6, as expected, but also for ccoaomt1-3. The weight of their inflorescence stem was reduced by $52 \%, 77 \%, 29 \%$, and $31 \%$ compared to the wild-type, respectively.

Prior to determining the cell wall composition, the senesced inflorescence stems were pooled two by two and a crude cell wall residue (CWR) of the dry stems was prepared through a sequential extraction with water, ethanol, chloroform, and acetone. Based on the weight loss by this sequential extraction, the dry stem biomass of the wild-type was calculated to be composed of approximately $78 \%$ CWR (Table 1). Similar values were obtained for the different mutants, except for $\operatorname{ccr} 1-3$ and 
ccr1-6, which had 14\% and 7\% less CWR (and thus more extractables) than the wild-type. For convenience, all further data are expressed on a CWR basis.

\section{Lignin amount and composition}

The lignin content was measured spectrophotometrically by the acetyl bromide (AcBr) method, adapted for small samples sizes (modified from [35]). Compared to the wild-type, the lignin content of both mutant alleles in C4H, 4CL1, CCoAOMT1, and CCR1 had decreased severely (Table 2 ). The strongest reduction was found for c4h-2 (-59\%), c4h-3 (-36\%), ccr1-3 (-51\%), and ccr1-6 $(-52 \%)$, whereas it was more moderate for the $4 c l 1$ and ccoaomt1 mutants (between 21 and 26\%).

Subsequently, the lignin composition was analyzed by thioacidolysis (Table 2) that quantifies the $\mathrm{H}, \mathrm{G}$, and $\mathrm{S}$ units that are linked by $\beta-\mathrm{O}-4$-ether bonds in the lignin polymer. The sum of $\mathrm{H}, \mathrm{G}$, and $\mathrm{S}$ is a good estimate of the total thioacidolysis yield and, thus, the condensation degree of the lignin polymer. The thioacidolysis yields of both mutant alleles of CCR1, ccr1-3 and ccr1-6, were reduced by $76 \%$ and $72 \%$. Less strong (but nevertheless significant) decreases in thioacidolysis yield were noticed for both $f 5 h 1$ and comt mutants and for $c 4 h-2$. The $\mathrm{H}$ units were barely detectable in the wild-type and comprised only $0.5 \%$ of the total identified thioacidolysisreleased units. Only the lignin in $c 4 h-2$ and the two mutant alleles of CCR1 had a relative increase in thioacidolysis-released $\mathrm{H}$ units. The relative amounts of thioacidolysis-released $\mathrm{G}$ units (\% G units) were reduced in both mutant alleles of $C 4 H, 4 C L 1$, and CCoAOMT1 and, except for the $c c r 1$ mutants, increased in other mutants of the monolignol-specific pathway. The relative amount of thioacidolysis-released S units (\% S units) followed an inverse relation with the $\mathrm{G}$ units: increased in $C 4 H, 4 C L 1$, and CCoAOMT1 and decreased in all mutants of the monolignol-specific pathway. Consequently, the S/G ratio, typically used to characterize the lignin composition, was increased for both mutant alleles of $C 4 H, 4 C L 1$, and CCoAOMT1, whereas it decreased in ccr1-3, cad6-4, and both mutant alleles of F5H1 and COMT.

In addition to the traditional lignin units $(\mathrm{H}, \mathrm{G}$, and $\mathrm{S})$, a number of minor "nonconventional" units were identified and quantified. Although the trace amounts of the 5-hydroxyguaiacyl (5-OH-G) units (derived from the incorporation of 5-hydroxyconiferyl alcohol into lignin) in wild-type plants are actual artefacts of the thioacidolysis procedure, the relative amount of the $5-\mathrm{OH}-\mathrm{G}$ units had increased in the comt mutants, consistent with previous reports of increased 5-OH-G units in COMTdeficient plants [31,36-39]. Units derived from the incorporation of coniferaldehyde and sinapaldehyde (the $G$ and $S$ aldehyde units) could be detected via thioacidolysis markers as previously described [40,41]. Mutants in the last step of the monolignol-specific pathway, CAD6, were characterized by a higher incorporation of $\mathrm{S}$ aldehydes than of $\mathrm{G}$ aldehyde units into the lignin polymer, in line with the higher substrate specificity of CAD6 for sinapaldehyde [42]. Finally, thioacidolysis released three different units derived from the incorporation of ferulic acid (FA) that is also a known minor constituent of lignin [43], two of which were linked via conventional $\beta-\mathrm{O}-4$-structures (the $\beta-\mathrm{O}-4-\mathrm{FA}-\mathrm{I}$ and $\beta-\mathrm{O}-4-\mathrm{FA}-\mathrm{II}$ units) and the third derived from the bis- $\beta-\mathrm{O}-4$-coupling of FA (the bis- $\beta$ O-4-FA unit) that results in a truncated side chain [43]. Of these three units, the relative abundance of bis- $\beta-\mathrm{O}-$ 4-FA was the highest. The relative abundance of $\beta-\mathrm{O}-$ 4-FA-I, $\quad \beta-O-4-F A-I I$, and bis- $\beta-O-4-F A$ units had increased in $c c r 1$ mutants, in agreement with previously reported results of $C C R$-deficient plants [43,44].

\section{Is lignin modification associated with altered cell wall polysaccharide amount and composition?}

To investigate whether perturbations in the lignin biosynthetic pathway also affected the abundance of the other cell wall polymers, we measured the cellulose content with the spectrophotometric phenol-sulfuric acid assay (adapted from $[45,46]$ ). In the adapted protocol, the CWR was hydrolyzed with trifluoroacetic acid (TFA) that extracts matrix polysaccharides, but also amorphous cellulose. Therefore, the data presented in Table 3 are estimates of the crystalline cellulose fraction. In Arabidopsis mutants deficient in the monolignol-specific pathway, from CCR1 through COMT, the decrease in crystalline cellulose content was the strongest for ccr1-3 $(-40 \%)$ and ccr1-6 $(-21 \%)$ whereas the mutant alleles of F5H1 and COMT had reductions of between 14\% and $19 \%$. All other mutants had similar crystalline cellulose contents to wild-type.

The mass loss during TFA extraction can be used as an estimate of the amount of matrix polysaccharides plus amorphous cellulose (Table 3). The CWR of the wild-type contained on average $36 \%$ matrix polysaccharides and amorphous cellulose, which is consistent with previous values [47]. However, mutants in the pathway from $C 4 H$ through $C C R 1$ had an increase in matrix polysaccharide content. Once more, the largest effects were noted for $c 4 h-2, c c r 1-3$, and $c c r 1-6$, with $21 \%, 31 \%$, and $25 \%$ increase compared to the wild-type, respectively, whereas it was moderate (between $6 \%$ and $11 \%$ ) for the $c 4 h-3$ mutant and both mutant alleles in $4 C L 1$, 4CL2, and CCOAOMT1.

The major monomeric sugars in the TFA extract quantified by gas chromatography/mass spectroscopy (GC/MS) were arabinose, xylose, and galactose. In both mutant alleles of CCR1 and $C 4 H$, the relative amounts of arabinose and galactose were significantly higher than 
Table 2 Lignin content and composition

\begin{tabular}{|c|c|c|c|c|c|c|c|c|c|c|c|c|}
\hline Line & $\mathrm{AcBr}$ & $H+G+S$ & $\% \mathrm{H}$ & $\%$ G & $\% \mathrm{~S}$ & $\%$ 5-OH-G & $\%$ bis- $\beta-0-4-F A$ & $\% \beta-0-4-F A-I$ & $\% \beta-0-4-F A-I I$ & $\begin{array}{l}\% \text { G } \\
\text { aldehydes }\end{array}$ & $\begin{array}{l}\% \text { S } \\
\text { aldehydes }\end{array}$ & S/G \\
\hline WT Col-0 & $14.5 \pm 0.6$ & $817.7 \pm 204.7$ & $0.5 \pm 0.1$ & $70.3 \pm 1.3$ & $29.0 \pm 1.4$ & $0.11 \pm 0.03$ & $0.07 \pm 0.03$ & $0.02 \pm 0.008$ & $0.01 \pm 0.005$ & $0.02 \pm 0.036$ & $0.01 \pm 0.006$ & $0.41 \pm 0.03$ \\
\hline pal1-2 & $14.0 \pm 0.6$ & $793.4 \pm 186.8$ & $0.5 \pm 0.1$ & $67.0 \pm 2.3$ & $32.3 \pm 2.3$ & $0.12 \pm 0.03$ & $0.06 \pm 0.03$ & $0.02 \pm 0.004$ & $0.01 \pm 0.005$ & $0.01 \pm 0.028$ & $0.02 \pm 0.009$ & $0.48 \pm 0.05$ \\
\hline pal1-3 & $13.9 \pm 0.8$ & $812.4 \pm 216.4$ & $0.5 \pm 0.2$ & $67.7 \pm 2.0$ & $31.5 \pm 2.0$ & $0.11 \pm 0.03$ & $0.05 \pm 0.03$ & $0.02 \pm 0.007$ & $0.01 \pm 0.002$ & $0.02 \pm 0.032$ & $0.01 \pm 0.005$ & $0.47 \pm 0.04$ \\
\hline pal2-2 & $14.1 \pm 1.0$ & $821.7 \pm 164.3$ & $0.5 \pm 0.2$ & $70.3 \pm 2.3$ & $29.0 \pm 2.2$ & $0.10 \pm 0.02$ & $0.07 \pm 0.02$ & $0.02 \pm 0.006$ & $0.01 \pm 0.004$ & $0.02 \pm 0.034$ & $0.02 \pm 0.008$ & $0.41 \pm 0.04$ \\
\hline pal2-3 & $14.2 \pm 0.9$ & $818.8 \pm 233.5$ & $0.4 \pm 0.1$ & $69.2 \pm 2.1$ & $30.2 \pm 2.0$ & $0.10 \pm 0.04$ & $0.05 \pm 0.02$ & $0.02 \pm 0.009$ & $0.01 \pm 0.005$ & $0.03 \pm 0.035$ & $0.01 \pm 0.011$ & $0.44 \pm 0.04$ \\
\hline$c 4 h-2$ & $6.0 \pm 0.4^{* *}$ & $530.7 \pm 160.8^{* *}$ & $1.9 \pm 0.8^{* *}$ & $55.7 \pm 2.6^{* *}$ & $42.1 \pm 2.5^{* *}$ & $0.15 \pm 0.03$ & $0.10 \pm 0.07$ & $0.03 \pm 0.012$ & $0.02 \pm 0.002$ & $0.02 \pm 0.020$ & $0.04 \pm 0.027$ & $0.76 \pm 0.08^{* *}$ \\
\hline$c 4 h-3$ & $9.3 \pm 0.3^{* *}$ & $870.7 \pm 248.7$ & $0.7 \pm 0.2$ & $53.5 \pm 2.1^{* *}$ & $45.6 \pm 2.1^{* *}$ & $0.13 \pm 0.02$ & $0.08 \pm 0.03$ & $0.02 \pm 0.008$ & $0.01 \pm 0.002$ & $0.01 \pm 0.026$ & $0.03 \pm 0.026$ & $0.86 \pm 0.07^{* *}$ \\
\hline $4 c / 1-1$ & $10.8 \pm 0.5^{* *}$ & $828.5 \pm 197.4$ & $0.8 \pm 0.3$ & $59.9 \pm 1.9^{* *}$ & $39.1 \pm 2.0^{* *}$ & $0.12 \pm 0.02$ & $0.10 \pm 0.04$ & $0.02 \pm 0.008$ & $0.01 \pm 0.003$ & $0.00 \pm 0.002$ & $0.03 \pm 0.023$ & $0.65 \pm 0.05^{* *}$ \\
\hline $4 c / 1-2$ & $10.8 \pm 0.7^{* *}$ & $804.4 \pm 151.9$ & $0.8 \pm 0.2$ & $60.6 \pm 2.7^{* *}$ & $38.3 \pm 2.1^{* *}$ & $0.11 \pm 0.05$ & $0.10 \pm 0.04$ & $0.02 \pm 0.010$ & $0.01 \pm 0.004$ & $0.02 \pm 0.055$ & $0.02 \pm 0.014$ & $0.63 \pm 0.06^{* *}$ \\
\hline $4 \mathrm{C} / 2-1$ & $14.3 \pm 0.7$ & $783.3 \pm 169.1$ & $0.5 \pm 0.2$ & $69.6 \pm 2.3$ & $29.6 \pm 2.3$ & $0.12 \pm 0.02$ & $0.07 \pm 0.03$ & $0.02 \pm 0.007$ & $0.01 \pm 0.003$ & $0.02 \pm 0.040$ & $0.01 \pm 0.004$ & $0.43 \pm 0.05$ \\
\hline $4 C 12-3$ & $14.0 \pm 0.5$ & $819.7 \pm 179.8$ & $0.5 \pm 0.1$ & $70.9 \pm 1.7$ & $28.3 \pm 1.8$ & $0.12 \pm 0.03$ & $0.08 \pm 0.03$ & $0.02 \pm 0.006$ & $0.01 \pm 0.004$ & $0.00 \pm 0.004$ & $0.01 \pm 0.009$ & $0.40 \pm 0.04$ \\
\hline ccoaomt1-3 & $11.4 \pm 1.7^{* *}$ & $789.3 \pm 156.8$ & $0.6 \pm 0.1$ & $62.3 \pm 4.4^{* *}$ & $36.7 \pm 4.3^{* *}$ & $0.13 \pm 0.03$ & $0.14 \pm 0.06$ & $0.04 \pm 0.010$ & $0.02 \pm 0.008$ & $0.02 \pm 0.029$ & $0.01 \pm 0.011$ & $0.60 \pm 0.11^{* *}$ \\
\hline ccoaomt1-5 & $10.9 \pm 0.4^{* *}$ & $696.1 \pm 187.9$ & $0.9 \pm 0.3$ & $60.7 \pm 2.9^{* *}$ & $38.0 \pm 3.0^{* *}$ & $0.12 \pm 0.03$ & $0.14 \pm 0.03$ & $0.08 \pm 0.113$ & $0.03 \pm 0.023$ & $0.03 \pm 0.036$ & $0.02 \pm 0.007$ & $0.63 \pm 0.08^{* *}$ \\
\hline ccrl-3 & $7.1 \pm 0.7^{* *}$ & $192.1 \pm 49.3^{* *}$ & $4.5 \pm 1.4^{* *}$ & $71.7 \pm 4.9$ & $18.5 \pm 5.0^{* *}$ & $0.23 \pm 0.11$ & $2.83 \pm 1.91^{* *}$ & $1.38 \pm 0.569^{* *}$ & $0.81 \pm 0.218^{* *}$ & $0.04 \pm 0.030$ & $0.09 \pm 0.048^{* *}$ & $0.26 \pm 0.09^{* *}$ \\
\hline ccrl-6 & $6.9 \pm 0.4^{* *}$ & $229.3 \pm 79.0^{* *}$ & $1.2 \pm 1.2^{*}$ & $68.7 \pm 2.6$ & $24.9 \pm 2.7^{* *}$ & $0.17 \pm 0.08$ & $2.55 \pm 1.04^{* *}$ & $1.61 \pm 0.366^{* *}$ & $0.94 \pm 0.317^{* *}$ & $0.05 \pm 0.061$ & $0.06 \pm 0.042$ & $0.36 \pm 0.05$ \\
\hline$f 5 h 1-2$ & $15.9 \pm 0.6^{*}$ & $596.0 \pm 167.4^{* *}$ & $0.4 \pm 0.1$ & $99.3 \pm 0.2^{* *}$ & $0.0 \pm 0.0^{* *}$ & $0.03 \pm 0.01$ & $0.10 \pm 0.05$ & $0.04 \pm 0.013$ & $0.02 \pm 0.008$ & $0.02 \pm 0.025$ & $0.01 \pm 0.009$ & $0.00 \pm 0.00^{* *}$ \\
\hline$f 5 h 1-4$ & $15.3 \pm 0.1$ & $595.6 \pm 137.0^{* *}$ & $0.4 \pm 0.1$ & $99.3 \pm 0.2^{* *}$ & $0.0 \pm 0.0^{* *}$ & $0.03 \pm 0.01$ & $0.08 \pm 0.04$ & $0.04 \pm 0.012$ & $0.03 \pm 0.007$ & $0.02 \pm 0.031$ & $0.01 \pm 0.003$ & $0.00 \pm 0.00^{* *}$ \\
\hline comt-1 & $13.7 \pm 1.0$ & $499.6 \pm 151.0^{* *}$ & $0.7 \pm 0.2$ & $97.7 \pm 0.6^{* *}$ & $0.5 \pm 0.1^{* *}$ & $0.93 \pm 0.32^{* *}$ & $0.09 \pm 0.04$ & $0.03 \pm 0.012$ & $0.02 \pm 0.009$ & $0.05 \pm 0.070$ & $0.02 \pm 0.025$ & $0.01 \pm 0.00^{* *}$ \\
\hline comt-4 & $14.1 \pm 0.9$ & $502.8 \pm 177.2^{* *}$ & $0.7 \pm 0.3$ & $94.9 \pm 0.6^{* *}$ & $3.2 \pm 0.4^{* *}$ & $0.94 \pm 0.35^{* *}$ & $0.10 \pm 0.02$ & $0.04 \pm 0.016$ & $0.02 \pm 0.018$ & $0.05 \pm 0.079$ & $0.01 \pm 0.007$ & $0.03 \pm 0.00^{* *}$ \\
\hline cad6-1 & $14.5 \pm 0.8$ & $779.7 \pm 183.7$ & $0.3 \pm 0.1$ & $73.7 \pm 2.1^{*}$ & $25.5 \pm 2.1^{*}$ & $0.10 \pm 0.02$ & $0.10 \pm 0.04$ & $0.02 \pm 0.006$ & $0.01 \pm 0.004$ & $0.04 \pm 0.061$ & $0.16 \pm 0.132^{* *}$ & $0.35 \pm 0.04$ \\
\hline cad6-4 & $14.4 \pm 0.7$ & $742.0 \pm 206.3$ & $0.3 \pm 0.1$ & $75.3 \pm 4.2^{* *}$ & $23.9 \pm 4.3^{* *}$ & $0.16 \pm 0.14$ & $0.09 \pm 0.02$ & $0.03 \pm 0.008$ & $0.01 \pm 0.005$ & $0.02 \pm 0.030$ & $0.18 \pm 0.122^{* *}$ & $0.32 \pm 0.07^{* *}$ \\
\hline
\end{tabular}

Lignin content and composition for the 20 lignin mutants $(n=8)$ and wild-type $(W T)(n=16)( \pm$ SD). Lignin content was determined with the AcBr assay and expressed as percentage CWR. Lignin composition was determined with thioacidolysis. The sum of $\mathrm{H}, \mathrm{G}$, and $\mathrm{S}$ is expressed in $\mu \mathrm{mol} \mathrm{g}^{-1} \mathrm{AcBr}$ lignin. The relative proportions of the different lignin units were calculated based on the total thioacidolysis yield (including the minor nonconventional lignin units). S/G was calculated based on the absolute values for $\mathrm{S}$ and $\mathrm{G}$ (expressed in $\mu$ mol $\mathrm{g}^{-1} \mathrm{AcBr}$ lignin). bis- $\beta-\mathrm{O}-4-\mathrm{F}-\mathrm{F}: \mathrm{G}-\mathrm{CHR}-\mathrm{CHR} \mathrm{R}_{2} ; \beta-\mathrm{O}-4-\mathrm{FA}-\mathrm{I}$ : G-CH $=\mathrm{CH}-\mathrm{COOH}$; $\beta-\mathrm{O}-4-\mathrm{FA}-\mathrm{Il}$ : $\mathrm{G}-\mathrm{CHR}-\mathrm{CH}_{2}-\mathrm{COOH}$. Increases and decreases compared to the wild-type are in bold and italics, respectively. ${ }^{*} 0.001<p<0.01 ;{ }^{* *} p<0.001$ (Dunnett-Hsu adjusted $t$-test). 
Table 3 Polysaccharide content and composition

\begin{tabular}{|c|c|c|c|c|c|c|c|c|c|c|c|}
\hline Line & Cellulose & $\begin{array}{l}\text { Matrix } \\
\text { polysaccharides }\end{array}$ & Rhamnose & Fucose & Arabinose & Xylose & Mannose & Glucose & Galactose & $\begin{array}{l}\text { Frequency of [Me]GlcA } \\
\text { branching of xylan }\end{array}$ & $\begin{array}{l}\% \text { methylatec } \\
\text { GlcA on xylan }\end{array}$ \\
\hline WT Col-0 & $38.9 \pm 2.3$ & $35.6 \pm 1.4$ & $3.4 \pm 0.1$ & $2.2 \pm 0.4$ & $12.7 \pm 0.4$ & $58.7 \pm 1.3$ & $2.8 \pm 0.2$ & $5.7 \pm 1.7$ & $14.5 \pm 0.3$ & $13.3 \pm 0.6$ & $64.9 \pm 0.6$ \\
\hline pal1-2 & $41.6 \pm 5.4$ & $35.7 \pm 1.8$ & $3.0 \pm 0.3^{* *}$ & $2.0 \pm 0.5$ & $13.2 \pm 0.4$ & $55.2 \pm 3.9^{*}$ & $2.3 \pm 0.3^{*}$ & $9.8 \pm 4.8$ & $14.5 \pm 0.4$ & $13.2 \pm 0.9$ & $66.3 \pm 0.8$ \\
\hline pal1-3 & $42.9 \pm 4.0$ & $37.3 \pm 1.1$ & $3.3 \pm 0.2$ & $2.3 \pm 0.3$ & $12.7 \pm 0.7$ & $56.0 \pm 3.0$ & $2.6 \pm 0.2$ & $8.9 \pm 4.2$ & $14.2 \pm 0.5$ & $13.2 \pm 1.0$ & $66.8 \pm 1.0$ \\
\hline pal2-2 & $41.5 \pm 4.6$ & $37.1 \pm 1.5$ & $3.5 \pm 0.1$ & $2.3 \pm 0.3$ & $12.6 \pm 0.8$ & $57.3 \pm 2.7$ & $2.9 \pm 0.2$ & $7.1 \pm 4.3$ & $14.4 \pm 0.8$ & $13.2 \pm 0.6$ & $64.2 \pm 1.0$ \\
\hline pal2-3 & $41.4 \pm 2.5$ & $36.8 \pm 1.7$ & $3.4 \pm 0.2$ & $2.3 \pm 0.2$ & $12.3 \pm 0.8$ & $56.7 \pm 3.4$ & $2.7 \pm 0.3$ & $8.7 \pm 5.1$ & $13.9 \pm 0.7$ & $13.1 \pm 0.9$ & $64.6 \pm 1.1$ \\
\hline$c 4 h-2$ & $36.3 \pm 2.1$ & $42.9 \pm 1.7^{* *}$ & $3.6 \pm 0.1$ & $2.7 \pm 0.4^{*}$ & $15.4 \pm 0.9^{* *}$ & $57.0 \pm 1.9$ & $2.8 \pm 0.1$ & $3.1 \pm 0.2$ & $15.4 \pm 0.9^{*}$ & $12.6 \pm 0.5$ & $80.3 \pm 1.2^{* *}$ \\
\hline$c 4 h-3$ & $40.7 \pm 3.0$ & $38.7 \pm 0.9^{* *}$ & $3.3 \pm 0.3$ & $2.5 \pm 0.4$ & $14.4 \pm 0.9^{* *}$ & $59.0 \pm 1.2$ & $2.8 \pm 0.4$ & $2.7 \pm 0.6$ & $15.5 \pm 1.0^{*}$ & $12.9 \pm 0.6$ & $72.1 \pm 1.5^{* *}$ \\
\hline $4 c / 1-1$ & $41.4 \pm 2.6$ & $37.8 \pm 1.4^{* *}$ & $3.5 \pm 0.2$ & $2.3 \pm 0.5$ & $13.3 \pm 0.4$ & $58.9 \pm 1.5$ & $2.9 \pm 0.2$ & $4.3 \pm 1.3$ & $14.8 \pm 0.3$ & $13.0 \pm 0.4$ & $74.7 \pm 1.8^{* *}$ \\
\hline $4 c 11-2$ & $40.7 \pm 2.8$ & $39.4 \pm 1.2^{* *}$ & $3.6 \pm 0.1$ & $2.2 \pm 0.4$ & $12.4 \pm 0.7$ & $58.6 \pm 1.6$ & $3.0 \pm 0.1$ & $6.2 \pm 1.8$ & $14.1 \pm 0.6$ & $13.1 \pm 1.0$ & $74.1 \pm 1.5^{* *}$ \\
\hline $4 C / 2-1$ & $37.8 \pm 2.2$ & $38.9 \pm 1.4^{* *}$ & $3.7 \pm 0.3^{* *}$ & $2.3 \pm 0.2$ & $12.1 \pm 1.0$ & $56.7 \pm 3.3$ & $2.8 \pm 1.1$ & $8.5 \pm 6.5$ & $13.8 \pm 0.9$ & $12.8 \pm 0.4$ & $64.5 \pm 0.6$ \\
\hline $4 C 12-3$ & $38.5 \pm 2.3$ & $38.3 \pm 1.3^{* * *}$ & $3.7 \pm 0.2^{* *}$ & $2.1 \pm 0.4$ & $12.0 \pm 0.4$ & $57.4 \pm 2.5$ & $3.1 \pm 0.2$ & $7.6 \pm 2.9$ & $14.0 \pm 0.3$ & $12.7 \pm 0.6$ & $63.8 \pm 1.2$ \\
\hline ccoaomt1-3 & $39.8 \pm 1.7$ & $39.6 \pm 1.4^{* *}$ & $3.8 \pm 0.2^{* *}$ & $2.4 \pm 0.1$ & $12.4 \pm 0.6$ & $59.6 \pm 1.2$ & $3.2 \pm 0.2$ & $3.8 \pm 0.8$ & $14.9 \pm 0.4$ & $13.4 \pm 0.7$ & $68.8 \pm 2.1^{* *}$ \\
\hline ccoaomt1-5 & $41.0 \pm 2.6$ & $38.4 \pm 1.4^{* *}$ & $3.4 \pm 0.1$ & $2.2 \pm 0.4$ & $13.5 \pm 1.4$ & $57.1 \pm 5.1$ & $3.0 \pm 0.6$ & $5.0 \pm 2.9$ & $15.8 \pm 1.4^{* *}$ & $13.5 \pm 0.4$ & $73.5 \pm 0.6^{* *}$ \\
\hline ccrl-3 & $23.4 \pm 3.5^{* *}$ & $46.6 \pm 1.5^{* *}$ & $3.1 \pm 0.3$ & $1.8 \pm 0.4$ & $19.2 \pm 1.3^{* *}$ & $50.3 \pm 2.2^{* *}$ & $2.4 \pm 0.3$ & $4.9 \pm 3.4$ & $18.2 \pm 1.0^{* *}$ & $14.2 \pm 0.4$ & $55.2 \pm 1.1^{* *}$ \\
\hline ccrl-6 & $30.9 \pm 2.6^{* *}$ & $44.6 \pm 1.3^{* *}$ & $3.6 \pm 0.3$ & $2.2 \pm 0.5$ & $15.7 \pm 0.4^{* *}$ & $54.1 \pm 1.9^{* *}$ & $2.7 \pm 0.1$ & $5.6 \pm 2.4$ & $16.0 \pm 0.5^{*}$ & $14.5 \pm 0.4$ & $54.9 \pm 1.8^{* *}$ \\
\hline$f 5 h 1-2$ & $31.7 \pm 2.0^{* *}$ & $35.7 \pm 1.3$ & $3.6 \pm 0.1$ & $2.1 \pm 0.5$ & $12.6 \pm 0.4$ & $57.0 \pm 1.9$ & $3.0 \pm 0.1$ & $7.4 \pm 2.2$ & $14.4 \pm 0.2$ & $13.0 \pm 0.7$ & $66.9 \pm 0.6$ \\
\hline$f 5 h 1-4$ & $32.8 \pm 3.2^{* *}$ & $35.8 \pm 1.3$ & $3.5 \pm 0.2$ & $2.0 \pm 0.4$ & $12.5 \pm 0.9$ & $55.6 \pm 3.7$ & $2.8 \pm 0.3$ & $9.2 \pm 5.5$ & $14.4 \pm 0.7$ & $13.0 \pm 0.3$ & $66.3 \pm 0.7$ \\
\hline comt-1 & $33.4 \pm 1.8^{* *}$ & $37.2 \pm 1.7$ & $3.4 \pm 0.2$ & $2.1 \pm 0.4$ & $12.7 \pm 0.7$ & $56.5 \pm 2.6$ & $2.9 \pm 0.2$ & $7.6 \pm 3.6$ & $14.8 \pm 0.4$ & $12.7 \pm 0.4$ & $65.6 \pm 1.9$ \\
\hline comt-4 & $33.2 \pm 2.1^{* *}$ & $36.1 \pm 0.9$ & $3.2 \pm 0.1$ & $2.2 \pm 0.4$ & $12.8 \pm 0.5$ & $55.2 \pm 2.6^{*}$ & $2.8 \pm 0.2$ & $7.9 \pm 3.4$ & $15.9 \pm 0.5^{* *}$ & $13.1 \pm 0.8$ & $65.2 \pm 0.6$ \\
\hline cad6-1 & $40.6 \pm 3.2$ & $34.8 \pm 1.2$ & $3.2 \pm 0.1$ & $2.3 \pm 0.5$ & $13.5 \pm 0.9$ & $58.8 \pm 1.6$ & $2.6 \pm 0.1$ & $5.1 \pm 2.7$ & $14.5 \pm 0.5$ & $13.0 \pm 0.5$ & $66.2 \pm 0.7$ \\
\hline cad6-4 & $38.9 \pm 3.3$ & $36.2 \pm 1.1$ & $3.3 \pm 0.1$ & $2.2 \pm 0.3$ & $12.7 \pm 0.5$ & $57.5 \pm 1.8$ & $2.8 \pm 0.1$ & $7.1 \pm 2.4$ & $14.4 \pm 0.6$ & $13.0 \pm 0.7$ & $66.4 \pm 0.5$ \\
\hline
\end{tabular}

Cellulose and matrix polysaccharide contents for the 20 lignin mutants $(n=8)$ and wild-type $(n=16)( \pm$ SD) were expressed as percentage CWR. Matrix polysaccharide content was determined gravimetrically based on a TFA extraction and its composition was expressed as mol\%. Xylan branching frequency and the percentage methylation of GIcA were determined by DASH. GlcA: glucuronic acid. Increases and decreases compared to the wild-type are indicated in bold and italics, respectively. ${ }^{*} 0.001<p<0.01 ;{ }^{* *} p<0.001$ (Dunnett-Hsu adjusted $t$-test). 
those of the wild-type, but the relative amount of xylose was significantly lower in both mutant alleles of CCR1. Although rhamnose, fucose, mannose, and glucose were present in minor quantities, small, but significant, changes could be observed for several mutants. Notably, the reduced amount of crystalline cellulose measured in ccr1, f5h1, and comt mutants was not accompanied by differences in glucose content in the TFA extract that could have been, partially, attributed to increases in amorphous cellulose, indicating that the $c c r 1, f 5 h 1$, and comt mutants indeed had lower levels of total cellulose.

In addition to the general matrix polysaccharide composition, more detailed information on the branching degree of xylan, as well as on the proportion of methylated glucuronic acid (GlcA) on xylan were established by DNA sequencer Assisted Saccharide analysis in High throughput (DASH). The branching degree of xylans was not affected in any of the lignin mutants, but the degree of xylan GlcA methylation was significantly reduced in both $c c r 1$ mutants and increased in both mutant alleles of C4H, 4CL1, and CCoAOMT1 (Table 3).

\section{Most lignin mutants have an improved saccharification yield}

To analyze whether the cell wall modifications in the mutant set affected the saccharification yield, a semihigh throughput protocol for small biomass samples $(10 \mathrm{mg})$ was established. Senesced stems of the lignin mutants and the wild-type were cut into $2-\mathrm{mm}$ pieces and saccharified for 48 hours, both without and with acid pretreatment. In this saccharification protocol, a relatively low amount of enzymes was used, allowing a low cellulose conversion into glucose. In this way, even subtle differences in saccharification yield between mutants and wild-type could be revealed.

Based on the measured cellulose content (Table 3) and the saccharification yields (Additional file 1), the cellulose conversion was calculated (Table 4). Under our saccharification conditions, approximately $16 \%$ and $18 \%$ of the cellulose was converted into glucose for the wildtype without and with acid pretreatment, respectively, whereas for the two mutant alleles of C4H, 4CL1, CCoAOMT1, CCR1, and COMT, the cellulose conversions were higher, both without and with acid pretreatment. The f5h1 mutants had higher cellulose conversions only without pretreatment. Saccharification after acid pretreatment resulted in cellulose conversions that were the highest for $c 4 h-2$, ccr1-3, and ccr1-6 (approximately 79\%, $88 \%$, and $77 \%$, respectively). This almost complete hydrolysis of cellulose in inflorescences of $c 4 h-2$ and $c c r 1$ mutants during saccharification was also visually noticeable; the structure of the stem segments was completely lost (Figure 2). Although $c 4 h-3$ and the mutant alleles of 4CL1, CCoAOMT1, F5H1, and COMT also had a
Table 4 Cellulose conversions and pretreatment effect

\begin{tabular}{|c|c|c|c|}
\hline Line & $\begin{array}{l}\text { Conversion without } \\
\text { (\% cellulose) }\end{array}$ & $\begin{array}{l}\text { Conversion with } \\
\text { (\% cellulose) }\end{array}$ & $\begin{array}{l}\text { Pretreatment } \\
\text { effect (\%) }\end{array}$ \\
\hline WT Col-0 & $16.3 \pm 2.2$ & $18.1 \pm 2.5$ & $11.2 \pm 3.3$ \\
\hline pal1-2 & $17.6 \pm 2.8$ & $18.5 \pm 5.7$ & $5.7 \pm 28.0$ \\
\hline pal1-3 & $16.8 \pm 2.0$ & $19.2 \pm 2.4$ & $14.5 \pm 3.7$ \\
\hline pal2-2 & $17.3 \pm 2.6$ & $19.1 \pm 3.4$ & $10.3 \pm 7.1$ \\
\hline pal2-3 & $16.8 \pm 1.6$ & $18.1 \pm 1.6$ & $8.0 \pm 7.0$ \\
\hline$c 4 h-2$ & $50.5 \pm 4.2^{* *}$ & $78.9 \pm 5.7^{* *}$ & $56.4 \pm 6.1^{* *}$ \\
\hline$c 4 h-3$ & $24.1 \pm 2.6^{* *}$ & $41.2 \pm 3.7^{* *}$ & $71.8 \pm 9.7^{* *}$ \\
\hline $4 c / 1-1$ & $21.2 \pm 2.1^{* *}$ & $30.8 \pm 5.1^{* *}$ & $44.9 \pm 14.7^{* *}$ \\
\hline $4 c / 1-2$ & $20.5 \pm 1.9^{* *}$ & $29.2 \pm 2.8^{* *}$ & $43.0 \pm 11.4^{* *}$ \\
\hline $4 C 12-1$ & $18.6 \pm 2.5$ & $20.3 \pm 2.0$ & $9.8 \pm 6.8$ \\
\hline $4 C 12-3$ & $17.9 \pm 1.0$ & $19.5 \pm 1.3$ & $8.9 \pm 3.6$ \\
\hline ccoaomt1-3 & $21.8 \pm 1.2^{* *}$ & $29.8 \pm 3.3^{* *}$ & $36.1 \pm 10.4^{*}$ \\
\hline ccoaomt1-5 & $20.4 \pm 4.6^{*}$ & $33.3 \pm 5.4^{* *}$ & $75.8 \pm 75.3^{* *}$ \\
\hline cCr $1-3$ & $77.9 \pm 14.6^{* *}$ & $88.3 \pm 12.8^{* *}$ & $14.5 \pm 11.1$ \\
\hline ccrl-6 & $64.0 \pm 4.8^{* *}$ & $76.8 \pm 5.6^{* *}$ & $20.1 \pm 6.1$ \\
\hline$f 5 h 1-2$ & $22.8 \pm 2.4^{* *}$ & $23.1 \pm 1.8$ & $1.6 \pm 3.3$ \\
\hline$f 5 h 1-4$ & $21.9 \pm 2.5^{* *}$ & $23.1 \pm 2.9$ & $5.8 \pm 6.9$ \\
\hline comt-1 & $24.8 \pm 0.4^{* *}$ & $28.5 \pm 1.3^{* *}$ & $14.9 \pm 4.8$ \\
\hline comt-4 & $25.4 \pm 3.0^{* *}$ & $28.2 \pm 2.3^{* *}$ & $11.4 \pm 6.1$ \\
\hline cad6-1 & $16.0 \pm 1.4$ & $17.9 \pm 1.8$ & $11.5 \pm 5.2$ \\
\hline cad6-4 & $17.8 \pm 1.9$ & $20.1 \pm 2.7$ & $13.2 \pm 5.2$ \\
\hline
\end{tabular}

Cellulose conversions for the 20 lignin mutants $(n=8)$ and the wild-type (WT) $(n=16)( \pm S D)$ without and with acid pretreatment were calculated based on the cellulose content and the saccharification yield (both on a CWR basis) and are expressed as percentage cellulose. The pretreatment effect illustrates the percentage increase in cellulose conversion due to the acid pretreatment compared to cellulose conversion without pretreatment and is calculated as follows: (conversion with - conversion without)/(conversion without) $\times 100=\%$. Increases compared to the wild-type are indicated in bold. ${ }^{*} 0.001<p<0.01$; ${ }^{* *} p<0.001$ (Dunnett-Hsu adjusted $t$-test).

cellulose-to-glucose conversion higher than that of the wild-type (albeit lower than that of the $c 4 h-2$ and ccr1 mutants), their inflorescence stem structure was maintained.

The acid pretreatment effect, which is the percentage increase in cellulose conversion due to the pretreatment, was comparable for most lignin mutants with that of the wild-type, i.e., between 2 and 20\%. Notable exceptions were the stems of both $c 4 h, 4 c l 1$, and ccoaomt1 mutants that were more susceptible to the acid pretreatment with a pretreatment effect between $36 \%$ and $76 \%$. None of the lignin mutants was more recalcitrant to the acid pretreatment than the wild-type (Table 4).

\section{Relations between lignin, cell wall polysaccharides, and saccharification yield}

To investigate the relations between the different cell wall components and their effect on the saccharification yield without and with acid pretreatment, we calculated 


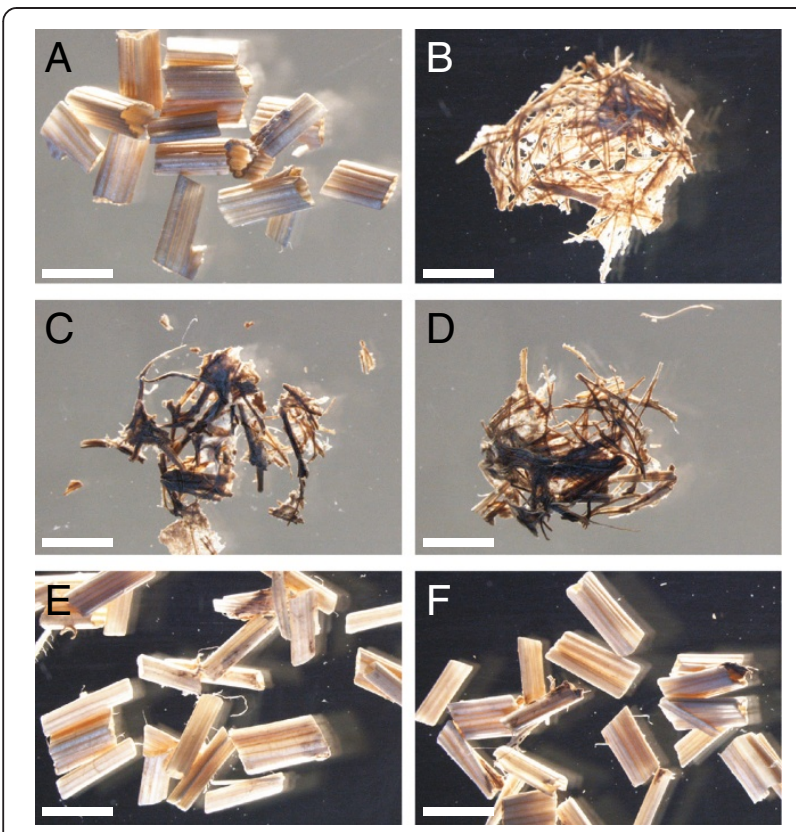

Figure 2 Cell wall degradation after saccharification. Stem material after $48 \mathrm{~h}$ of saccharification (including acid pretreatment). (A) Wild-type. The structure of stem segments of the mutants c $4 \mathrm{~h}-2$ (B), ccr1-3 (C), and ccr1-6 (D) are fully degraded as a consequence of the almost complete conversion of cellulose into glucose. Although the cellulose conversion was also improved in other mutants, such as $c 4 h-3(\mathbf{E})$ and $4 c / 1-1(\mathbf{F})$, the stem structure remained intact. Scale bar $=2 \mathrm{~mm}$.

the Pearson correlations (Figure 3, Additional file 2, and Additional file 3) based on the compositional data (Tables 2 and 3) and the saccharification data (Table 4 and Additional file 1). However, the data for the three phenotypically abnormal mutants (c4h-2, ccrl-3, and ccr1-6) had too large an effect on the correlations; to minimize the occurrence of high correlations caused by outliers from $c 4 h-2$, ccr1-3, and ccr1-6 mutants, these three mutants were left out of the analysis. The correlation matrix revealed that a reduction in lignin content was compensated for by an increase in matrix polysaccharides $(\mathrm{r}=-0.49, p<0.0001)$ rather than by an increase in cellulose $(\mathrm{r}=-0.34, p<0.0001)$, even though the correlation coefficient between lignin and matrix polysaccharides indicated only a weak, and not a strong, relationship. The glucose yields upon saccharification without and with acid pretreatment were correlated $(\mathrm{r}=0.80, p<0.0001)$. Furthermore, the saccharification yield was negatively influenced by the amount of lignin $(\mathrm{r}=-0.65, p<0.0001$ without pretreatment; $\mathrm{r}=-0.83, p<0.0001$ with acid pretreatment). In addition, the data implied that the lignin content played a larger role in determining saccharification yield than the lignin $\mathrm{S} / \mathrm{G}$ composition $(\mathrm{r}=-0.65, p<$ 0.0001 and $\mathrm{r}=0.31, p=0.0001$ for saccharification without pretreatment, respectively; $\mathrm{r}=-0.83, p<0.0001$ and $\mathrm{r}$ $=0.59, p<0.0001$ for saccharification with pretreatment, respectively). This correlation matrix also revealed that the matrix polysaccharide content influenced the saccharification yield to some extent $(\mathrm{r}=0.42, p<0.0001$ for saccharification without pretreatment; $\mathrm{r}=0.48, p<0.0001$ with acid pretreatment), whereas cellulose did not $(r=$ $-0.01, p=0.8769$ for saccharification without pretreatment; $\mathrm{r}=0.13, p=0.1018$ for saccharification with acid pretreatment).

Next, models were made that described how the different cell wall polymers influenced the saccharification yield (Table 5 and Additional file 4). By modeling the saccharification yield (Additional file 1) and not the cellulose conversion (Table 4), the cell wall parameter "crystalline cellulose content" could be included into the model. The other cell wall parameters that were considered to influence the saccharification yield and, hence, design the saccharification model were the amount of lignin and matrix polysaccharides, the $S / G$ ratio, the abundance of ferulic acid, and the three main matrix monosaccharides arabinose, galactose, and xylose. For the three monosaccharides, the absolute amounts (Additional file 5) were used to build the models instead of the molar proportions (Table 3), because the relative proportions for these sugars are intrinsically linked with each other. Generally, the models confirmed the correlation matrix and explained $70 \%$ and $71 \%$ of the saccharification yield variations without and with acid pretreatment, respectively (Table 5). When saccharification was performed without pretreatment, the lignin amount had the strongest negative impact on the saccharification yield, followed by the S/G ratio, xylose, and ferulic acid content. Galactose and the amount of matrix polysaccharides contributed positively to the saccharification yield without pretreatment. Similarly, for saccharification with acid pretreatment, the lignin content and xylose had a negative impact and only galactose, but not the other matrix polysaccharides sugars or content, positively influenced the saccharification yield with acid pretreatment.

In addition, the increase in saccharification yield that was attributable to the acid pretreatment, represented as the "pretreatment effect", was also negatively influenced by the lignin content and xylose, but positively by the S/G ratio and galactose (Table 5). Because arabinose was correlated with galactose $(\mathrm{r}=0.94, p<0.001)$, arabinose was left out of the model, but it would influence the saccharification yield and pretreatment effect in a similar way as galactose. Strikingly, cellulose content did not affect the saccharification yield, neither without, nor with pretreatment, and did not influence the pretreatment effect.

\section{Discussion}

Two mutant alleles for 10 genes of the phenylpropanoid and monolignol biosynthetic pathways were grown 


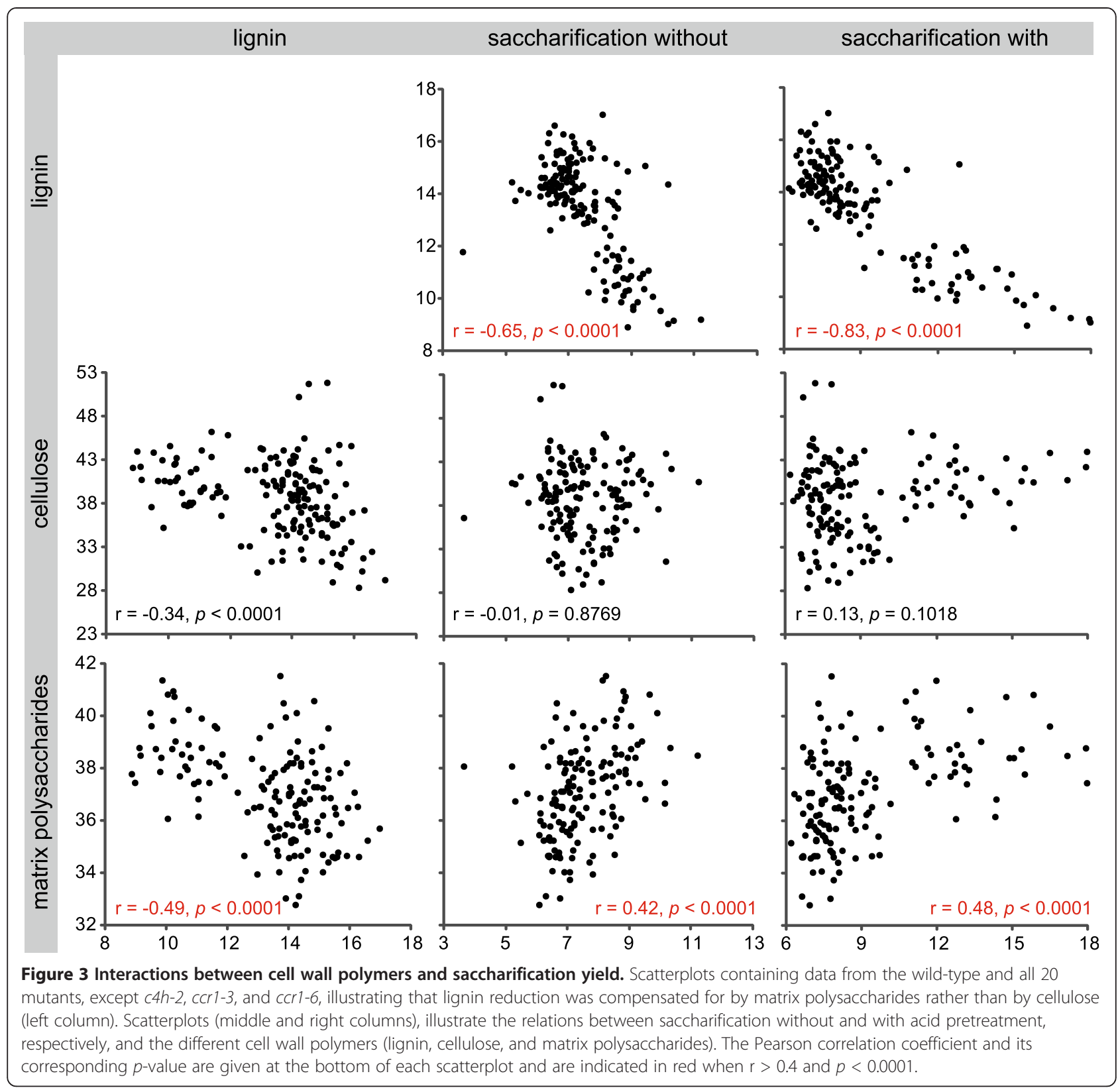

together with the wild-type and their senesced inflorescences analyzed for cell wall composition (lignin content, lignin S/G composition, nonconventional lignin units, crystalline cellulose content, and matrix polysaccharide content and composition) and saccharification yields without and with acid pretreatment. The high number of mutants analyzed allowed us to make system-wide correlations among the various parameters. In addition, we proposed saccharification models in which the saccharification yield was considered as a function of the cell wall composition that identified the major cell wall recalcitrance-determining factors.

\section{System-wide effects on lignin}

Although the lignin biosynthetic pathway has been studied extensively by means of reverse and forward genetics [48], the systematic side-by-side comparison of the 20 mutants, each defective in a single gene of the lignin biosynthetic pathway, revealed a number of novel observations. First, the $c 4 h, 4 c l 1$, ccoaomt1, and ccrl mutants had a reduced lignin content, but not $4 c l 2$, probably because $4 C L 2$ has a 10 -fold lower substrate specificity for 4-coumarate than 4CL1 [49]. The pal1 and pal2 mutants had normal lignin levels, presumably because of gene redundancy. Indeed, the pal1 
Table 5 Models for saccharification yield and pretreatment effect

\begin{tabular}{|c|c|c|c|c|}
\hline Cell wall factor & Parameter estimate & Standard error & $p$-value & $\begin{array}{l}\text { Standardized } \\
\text { estimate }\end{array}$ \\
\hline \multicolumn{5}{|c|}{ Saccharification model without pretreatment } \\
\hline Intercept & 0.09536 & 0.01308 & $<0.0001$ & 0.00 \\
\hline Lignin & -0.52154 & 0.04720 & $<0.0001$ & -0.89 \\
\hline$S / G$ & -0.01170 & 0.00318 & 0.0003 & -0.29 \\
\hline Ferulic acid & -4.24820 & 1.27867 & 0.0011 & -0.15 \\
\hline Galactose & 0.00223 & 0.00066 & 0.0009 & 0.24 \\
\hline Xylose & -0.00044 & 0.00015 & 0.0043 & -0.19 \\
\hline Matrix polysaccharides & 0.07289 & 0.03156 & 0.0224 & 0.13 \\
\hline \multicolumn{5}{|c|}{ Saccharification model with acid pretreatment } \\
\hline Intercept & 0.52417 & 0.04977 & $<0.0001$ & 0.00 \\
\hline Lignin & -8.14968 & 0.89507 & $<0.0001$ & -5.33 \\
\hline Lignin $^{2}$ & 35.18722 & 4.45747 & $<0.0001$ & 4.61 \\
\hline Galactose & 0.00538 & 0.00149 & 0.0004 & 0.22 \\
\hline Xylose & -0.00120 & 0.00036 & 0.0010 & -0.20 \\
\hline \multicolumn{5}{|c|}{ Pretreatment effect model } \\
\hline Intercept & 0.29129 & 0.04709 & $<0.0001$ & 0.00 \\
\hline Lignin & -5.35810 & 0.79704 & $<0.0001$ & -4.91 \\
\hline Lignin $^{2}$ & 24.30648 & 3.91171 & $<0.0001$ & 4.46 \\
\hline$S / G$ & 0.01737 & 0.00693 & 0.0133 & 0.23 \\
\hline Galactose & 0.00384 & 0.00144 & 0.0087 & 0.22 \\
\hline Xylose & -0.00091 & 0.00033 & 0.0058 & -0.21 \\
\hline
\end{tabular}

Models illustrate which cell wall factors had a significant influence on the saccharification yield or pretreatment effect. The "parameter estimate" indicates the increase in saccharification yield or pretreatment effect when 1 unit of the cell wall factor is increased when the other cell wall factors are fixed. The standardized

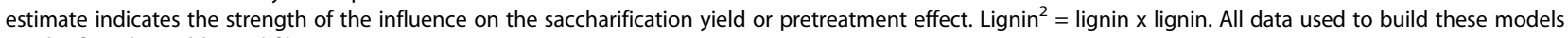
can be found in Additional file 4.

pal2 pal3 pal4 quadruple mutant had only $20-25 \%$ of residual lignin [50]. As F5H1, COMT, and CAD are specific for the biosynthesis of $\mathrm{S}$ units, disruption of these genes has a larger impact on the lignin composition than on the lignin content. Although lignin is a load-bearing polymer in the secondary cell wall, most lignin mutants had no obvious morphological phenotypes, despite a reduced lignin content. For example, the $4 c l 1$ mutants maintained a normal phenotype with $26 \%$ reduced lignin levels and even the $c 4 h-3$ mutant with a lignin content of only $64 \%$ of that of the wildtype grew normally under our growth conditions.

Second, the lignin composition as analyzed via thioacidolysis clearly differed in mutants of the general phenylpropanoid pathway $(C 4 H, 4 C L 1$, and CCoAOMT1 with an increase in the S/G ratio) and the monolignolspecific pathway (from CCR1 through CAD6 with a decrease in the $\mathrm{S} / \mathrm{G}$ ratio). Because $F 5 H 1$ and COMT are specific for $\mathrm{S}$ biosynthesis, it is not surprising that the f5h1 and comt mutants lack S units. Given that S biosynthesis increases during stem development [51], the decrease in $\mathrm{S}$ units in the $c c r 1$ mutants can be attributed to their slower and probably incomplete development $[34,52,53]$. The reduction in the $S$ unit content can easily be explained for the ccrl, f5h1, and comt mutants, but the increase in $\mathrm{S}$ units in the $c 4 h$ and $4 c l 1$ mutants is more difficult to explain from the linear pathway presented in Figure 1. Most likely, the residual flux through the phenylpropanoid pathway preferentially proceeds toward $\mathrm{S}$ units when $\mathrm{F} 5 \mathrm{H} 1$ and COMT remain fully active, because $\mathrm{F} 5 \mathrm{H} 1$ is known to be the rate-limiting step in sinapyl alcohol biosynthesis [54]. Alternatively, in the mutants, feedback and feed-forward mechanisms can alter the flux through the different steps of the lignin biosynthetic pathway $[32,55]$.

Third, both mutant alleles of CCR1 had a relative increase in thioacidolysis-released $\mathrm{H}$ units. The accumulation of $\mathrm{H}$ units in the $c \mathrm{cr} 1$ mutants is puzzling because the corresponding enzyme is positioned before the biosynthesis of $\mathrm{H}$ units; however, microarray data of inflorescence stems of the $c c r 1$ mutants revealed that the transcript level of CCR2 (and not of CCR1) was higher than that of the wild-type [32], and might contribute to 
the formation of $\mathrm{H}$ units [56]. Hence, a possible redirection of the pathway could be that the CCR2 activity takes the flux partially to $\mathrm{H}$ units in the $c \mathrm{cr} 1$ mutants. The potential involvement of $C C R 2$ in the production of $\mathrm{H}$ units has recently been suggested in alfalfa as well [55]. Nevertheless, additional enzyme kinetics and flux studies are needed to demonstrate these alternative pathways.

Fourth, compounds derived from an incomplete monolignol biosynthesis often incorporate into the lignin polymer of lignin biosynthesis mutants [57]. In line with previous reports, 5-OH-G units, FA-derived units, and $\mathrm{S}$ aldehyde units were evidenced in lignin of COMT-deficient [31], CCR-deficient [43,44], and CAD-deficient plants [40-42], respectively. Analysis of the lignin composition of the entire set of lignin mutants revealed that these nonconventional lignin units are specific for the mutants described above and do not occur at high levels in the other lignin mutants analyzed.

\section{Relations between lignin and cell wall polysaccharides} Perturbations in the lignin biosynthetic pathway have been shown to have far-reaching consequences on the transcriptome and metabolome [32,55,58-61]. The scientific literature often suggests that reductions in lignin amount are compensated for by increases in cellulose content [29,31]. In contrast, we did not observe such a compensation in Arabidopsis. None of the mutants displayed an increase in cellulose content at senescence or in cellulose synthase (CesA) transcript levels, as analyzed by microarrays [32]. Instead, the reduction in lignin levels in the $c 4 h, 4 c l 1$, ccoaomt1, and ccrl mutants was rather associated with an increase in matrix polysaccharide levels, according to the weight loss after a TFA extraction (Figure 3, Additional file 2, and Additional file 3). Besides an effect on the matrix polysaccharide content, its composition was also affected by the mutations in the lignin biosynthetic pathway. The differences were the largest in the $c 4 h$ and $c c r 1$ mutants, although a large proportion of these differences in the $c c r 1$ mutants could potentially be due to the altered development rather than to a compensation mechanism. Although in some lignin mutants the matrix polysaccharide composition was slightly altered, no obvious correlations were found between lignin content or composition and matrix polysaccharide composition. However, whereas all mutants had similar levels of branching xylans, the $c 4 h, 4 c l 1$, and ccoaomt 1 mutants had strikingly more and the $c c r 1$ mutants less methylation of GlcA. Previously, increases in GlcA methylation on xylan had been observed only in xylan biosynthesis mutants [6]. However, more in-depth studies are needed to fully understand how the lignin and matrix polysaccharide pathways are interconnected.

Another remarkable observation was the decreased cellulose content in the ccrl, f5h1, and comt mutants.
The low cellulose amount in both $c c r 1$ mutants might possibly be due to their altered development $[34,52,53,62]$, but the $f 5 h 1$ and comt mutants developed normally, albeit with reduced cellulose contents. Common to all mutants with a decreased cellulose content ( $c c r 1, f 5 h 1$, and comt) is the release of fewer $\mathrm{S}$ units upon thioacidolysis and, consequently, a decreased S/G ratio and a high lignin condensation $(H+G+S)$ (Table 2 and Additional file 6). Mutants with increased S content and S/G ratio (c4h, $4 c l 1$, and ccoaomt1) had a cellulose content similar to that of the wild-type. These data suggest that when the S/G ratio drops below a certain level, the crystalline cellulose content in the cell wall decreases. In contrast, when the S/G ratio is elevated, at least ranging from 0.41 in the wild-type up to 0.86 in the $c 4 h-3$ mutant (Table 2), the crystalline cellulose content remained equal to that of the wild-type. The positive correlation between lignin composition (S/G) and cellulose also follows from the Pearson correlation coefficient in the correlation matrix $(\mathrm{r}=0.57$, $p<0.0001$ ) (Additional file 3). A correlation between the S/G ratio and cellulose had also been found recently in eucalyptus by studying natural variation in wood properties [63]. These observations raise the question as whether monolignol biosynthesis affects cellulose deposition directly or indirectly, especially because lignin is supposed to be deposited mainly in the secondary cell wall after completion of the cellulose biosynthesis [7].

Lignin content, lignin composition, galactose, xylose, and matrix polysaccharide content, but not cellulose content, affect saccharification yield

Based on the lignin content and saccharification yield of the different mutants (Tables 2 and 4) and the correlation matrix (Figure 3, Additional file 2, and Additional file 3), it is clear that saccharification yield is highly influenced by the lignin content, as also shown in alfalfa [3]. However, in both mutant alleles of COMT, an increase in the saccharification yield occurred without and with acid pretreatment, but no decrease in lignin content. These exceptions indicate that other cell wall parameters, besides lignin content, influence saccharification.

Saccharification of the $f 5 h 1$ mutants (low S/G) and overexpression of the Arabidopsis F5H1 gene (high S/G) revealed that the lignin composition (via the traditional monomers) had no influence on the saccharification yield without pretreatment, but high $\mathrm{S}$ lignins had an improved saccharification after pretreatment with hot water [23]. Similar observations with a hot water pretreatment were found for saccharification of wood from natural poplar variants [19]. In contrast, in our saccharification models, which are based on a range of $S / G$ ratios and not on extreme S/G ratios only and use a pretreatment different from hot water, the S/G ratio had a negative effect when no pretreatment was included, but 
not when an acid pretreatment preceded the saccharification (Table 5). This suggests that cell walls with a high $\mathrm{S} / \mathrm{G}$ ratio, form a matrix in which the matrix polysaccharides (that are the targets for acid pretreatment) render the cellulose less accessible by cellulases.

The saccharification models clearly revealed that the lignin content was the main factor determining saccharification, whether a pretreatment was included or not. When saccharification was carried out without a pretreatment, the S/G lignin composition, ferulic acid content, and xylose content also negatively influenced the saccharification yield, whereas matrix polysaccharide content and galactose had a positive effect. The saccharification yield with acid pretreatment was only influenced negatively by the lignin and xylose contents and positively by the galactose content. Because arabinose was positively correlated with galactose, it would influence saccharification yield in a similar way as galactose. For example, a $10 \%$ increase in saccharification yield with pretreatment, as compared to wild-type (i.e., from 0.059 to $0.065 \mathrm{mg} / \mathrm{mg}$ dry weight), can be obtained by a lignin reduction of $9.9 \%$ (i.e., from 0.114 to $0.103 \mathrm{mg} / \mathrm{mg}$ dry weight). A similar increase in saccharification yield could also be achieved by increasing the galactose content by $8.5 \%$ (i.e., from 12.9 to $14.0 \mu \mathrm{g} / \mathrm{mg}$ dry weight), increasing the arabinose content by $12 \%$ (i.e., from 11.0 to 12.4 $\mu \mathrm{g} / \mathrm{mg}$ dry weight), or decreasing the xylose content by 9.5\% (i.e., from 52.1 to $47.2 \mu \mathrm{g} / \mathrm{mg}$ dry weight). Remarkably, without or with acid pretreatment, the cellulose content was not important for the saccharification yield. However, only $70 \%$ and $71 \%$ of the variation in saccharification yield without and with pretreatment, respectively, could be explained by these saccharification models, indicating that factors other than the ones examined here might still play a role in cell wall recalcitrance. Importantly, it is intrinsic to models that they only predict the outcome within the range of the data. Care must thus be taken by extrapolating the predicted effects beyond that range.

\section{Conclusions}

Two mutant alleles for 10 genes of the phenylpropanoid and monolignol biosynthetic pathways were grown together with the wild-type and analyzed for their cell wall composition and saccharification yield. Our data suggest that, at least in Arabidopsis, the reduction in lignin is not compensated for by an increase in cellulose, but rather by an increase in matrix polysaccharides. The mutants $c 4 h-2, c c r 1-3$, and $c c r 1-6$, with the largest reduction in lignin content, had the highest saccharification yields and an almost complete cellulose conversion that resulted in a stem structure disintegration. The saccharification models indicated that lignin content was the main factor determining saccharification yield. Without pretreatment, also lignin composition played a role, whereas with acid pretreatment lignin composition was not important anymore. In both cases, without and with acid pretreatment, other cell wall factors, such as xylose, galactose, and arabinose contents, affected the saccharification yields. Our results contribute to a better understanding of the effect of lignin perturbations on plant cell wall composition and its influence on saccharification yield. These results provide new potential targets for genetic improvement, such as the biosynthesis of arabinogalactan, mannans, or xyloglucans to increase the galactose content.

\section{Methods}

\section{Plant material}

For 10 different genes involved in lignin biosynthesis, two Arabidopsis thaliana (L.) Heyhn. mutant alleles were used in this study, including pal1-2, pal1-3, pal2-2, pal2-3, c4h-2, c4h-3, 4cl1-1, 4cl1-2, 4cl2-1, 4cl2-3, ccoaomt1-3, ccoaomt1-5, ccr1-3, ccr1-6, f5h1-2, f5h1-4, comt-1, comt-4, cad6-1, and cad6-4. For a schematic presentation of the 20 mutants and their residual expression, see Vanholme et al. [32]. Sixteen biological replicates of each homozygous mutant and 32 biological replicates for the wild-type were grown simultaneously in a random block design, spread over different trays, in the same environment. Because of their delayed development, $c 4 h-2, c c r 1-3$, and ccr1-6 were planted 2 weeks in advance to allow simultaneous bolting. Plants were grown first under short-day conditions $\left(8 \mathrm{~h} \mathrm{light,} 21^{\circ} \mathrm{C}\right.$, and 55\% humidity) during 6 weeks and then transferred to long-day conditions ( $16 \mathrm{~h}$ light, $21^{\circ} \mathrm{C}$, and $55 \% \mathrm{hu}$ midity) to allow the development of a single tall inflorescent stem. For all biological repeats, the main stem was harvested just above the rosette when the plant was completely senesced and dry. Once harvested, rosette leaves, axillary inflorescences, and siliques were removed. The main stem was weighed and the bottom $1 \mathrm{~cm}$ was removed. The lowest $10 \mathrm{~cm}$ of the remaining stem was chopped in 2-mm pieces. Biological repeats were pooled two by two to obtain 8 biological replicates for the mutant alleles and 16 repeats for the wild-type. These pooled samples were used for wet-chemistry cell wall analyses and saccharification assays.

\section{Lignin analyses}

Aliquots of $5 \mathrm{mg}$ stem pieces were subjected to a sequential extraction to obtain a purified CWR. The extractions were done in 2-ml vials, each time for $30 \mathrm{~min}$, at near boiling temperatures for water $\left(98^{\circ} \mathrm{C}\right)$, ethanol $\left(76^{\circ} \mathrm{C}\right)$, chloroform $\left(59^{\circ} \mathrm{C}\right)$, and acetone $\left(54^{\circ} \mathrm{C}\right)$. The remaining CWR was dried under vacuum. Lignin was quantified according to a modified version of the acetyl bromide method [35], optimized for small amounts of plant tissue. The dried CWR was dissolved in $0.1 \mathrm{ml}$ freshly made $25 \%$ 
acetyl bromide in glacial acetic acid and $4 \mu \mathrm{l} 60 \%$ perchloric acid. The solution was incubated for $30 \mathrm{~min}$ at $70^{\circ} \mathrm{C}$ while shaking $(850 \mathrm{rpm})$. After incubation, the slurry was centrifuged at $23,477 \mathrm{~g}$ for $15 \mathrm{~min}$. To the supernatant, $0.2 \mathrm{ml}$ of $2 \mathrm{M}$ sodium hydroxide and $0.5 \mathrm{ml}$ glacial acetic acid were added. The pellet was washed with $0.5 \mathrm{ml}$ glacial acetic acid. The supernatant and the washing phase were combined and the final volume was adjusted to $2 \mathrm{ml}$ with glacial acetic acid. After $20 \mathrm{~min}$ at room temperature, the absorbance at $280 \mathrm{~nm}$ was measured with a NanoDrop ${ }^{\oplus}$ ND-1000 spectrophotometer (Thermo Scientific, Wilmington, DE, USA). The lignin concentrations were calculated by means of the Bouguer-LambertBeer law: $\mathrm{A}=\varepsilon \times 1 \times \mathrm{c}$, with $\varepsilon=23.35 \mathrm{l} \mathrm{g}^{-1} \mathrm{~cm}^{-1}$ [64] and $1=0.1 \mathrm{~cm}$.

The lignin composition was investigated with thioacidolysis as previously described [65]. The monomers involved in $\beta-\mathrm{O}-4$-ether bonds, released upon thioacidolysis, were detected with gas chromatography (GC) as their trimethylsilyl (TMS) ether derivatives on a Hewlett-Packard HP 6890 Series GC system (Agilent, Santa Clara, CA, USA) coupled with a HP-5973 massselective detector. The GC conditions were as described [65]. The quantitative evaluation was carried out based on the specific prominent ions for each compound. A summary of the specific ions for each identified compound can be found in Additional file 7. Response factors for $\mathrm{H}, \mathrm{G}$, and $\mathrm{S}$ units were taken from [66]. Because we had no standards for the minor lignin units, a response factor of 0.47 was used, which is the average of the three response factors for the major lignin units.

\section{Polysaccharide analyses}

Aliquots of $4 \mathrm{mg}$ dry stem pieces were sequentially extracted to obtain a purified CWR, as described above. To estimate the amount of cellulose, we used a colorimetric method (based on $[45,46])$. The CWR was incubated with $2 \mathrm{M}$ TFA and $20 \mu \mathrm{l}$ inositol $\left(5 \mathrm{mg} \mathrm{ml}^{-1}\right)$ for $2 \mathrm{~h}$ at $99^{\circ} \mathrm{C}$ while shaking $(750 \mathrm{rpm})$. This TFA extract was used for the determination of the sugar composition of matrix polysaccharides (see below). After incubation, the remaining pellet was washed three times with water and twice with acetone and dried under vacuum. Concentrated sulfuric acid $(150 \mu \mathrm{l})$ and $30 \mu \mathrm{l} 5 \%(\mathrm{w} / \mathrm{v})$ phenol (freshly made in water) were added to the dried pellet and incubated for $1 \mathrm{~h}$ at $90^{\circ} \mathrm{C}$ with gentle shaking (500 rpm). After centrifugation for $3 \mathrm{~min}$ at 23,477 $\mathrm{g}$, a $50 \mu \mathrm{l}$ aliquot of the supernatant was diluted 20 times with MilliQ water (Millipore, Billerica, MA, USA) to measure the absorbance at $493 \mathrm{~nm}$. The amount of cellulose was calculated back from a standard curve of Avicel ${ }^{\circ}$ PH-101 (FMC BioPolymer, Philadelphia, PA, USA).

To determine the different monosaccharides present in the TFA extract, $800 \mu \mathrm{l}$ TFA extract was dried under vacuum and further converted to the corresponding alditol acetates as described [67]. The GC-MS analyses were carried out with a mass-selective detector (HP 5973 model; Agilent), interfaced to a GC (HP 6890 model; Agilent) equipped with an automated sample injector and an VF- $5 \mathrm{~ms}$ capillary column $(30 \mathrm{~m} \times 0.25 \mathrm{~mm}$ ). The GC conditions were as described [68]: the oven was kept at $100^{\circ} \mathrm{C}$ for $1 \mathrm{~min}$, increasing the temperature to $245^{\circ} \mathrm{C}$ at a

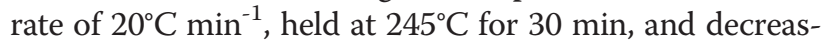
ing the temperature to a final temperature of $100^{\circ} \mathrm{C}$ at a rate of $30^{\circ} \mathrm{C} \mathrm{min}{ }^{-1}$. Peak areas of the different sugars were normalized with the peak area of the internal standard inositol $\left(20 \mu \mathrm{l}, 5 \mathrm{mg} \mathrm{ml}^{-1}\right)$. Response factors were determined based on standard curves for each of the different sugars: rhamnose (2.01), fucose (2.05), arabinose (1.35), xylose (1.35), mannose (1.45), glucose (1.59), and galactose (1.55).

\section{Analysis of xylan structure}

Senesced stems (10 mg) from five biological replicates of each genotype were incubated at $70^{\circ} \mathrm{C}$ in $96 \%$ ethanol for $20 \mathrm{~min}$ and then homogenized using a ball mixer mill (Glen Creston, London, UK). The insoluble material was washed with $100 \%$ ethanol, twice with chloroform: methanol (2:1), and then successively washed with $65 \%$, $80 \%$, and $100 \%$ ethanol prior to air drying to produce an alcohol-insoluble residue (AIR). AIR (100 $\mu \mathrm{g})$ was pretreated with $4 \mathrm{M} \mathrm{NaOH}(20 \mu \mathrm{l})$ for $1 \mathrm{~h}$ at $21^{\circ} \mathrm{C}$ to make the xylan enzyme accessible, neutralized, and then resuspended in $500 \mu \mathrm{l} 0.1 \mathrm{M}$ ammonium acetate buffer ( $\mathrm{pH}$ 5.5). Samples were incubated overnight at $21^{\circ} \mathrm{C}$ with an excess of the xylanase NpXyn11A (a kind gift of Harry Gilbert, University of Newcastle, UK) to ensure complete digestion.

The samples were dried under vacuum and analyzed by DNA sequencer Assisted Saccharide analysis in High throughput (DASH). The xylanase-released oligosaccharides or quantitation standards and appropriate controls were derivatized with 8-aminopyrene-1,3,6-trisulfonic acid (APTS; Biotium, Hayward, CA, USA). The dried oligosaccharide sample was combined with $10 \mu \mathrm{l}$ APTS (0.02 $\mathrm{M}$ in $1.2 \mathrm{M}$ citric acid) and $10 \mu \mathrm{l} 0.1 \mathrm{M} \mathrm{NaCNBH}_{3}$ solutions. Following overnight incubation $\left(30^{\circ} \mathrm{C}\right)$, the samples were diluted to $1 \mu \mathrm{g} \mathrm{ml}^{-1}$ initial AIR, of which 10 to $30 \mu \mathrm{l}$ were loaded into a 96-well microtiter plate, and analyzed by capillary electrophoresis with a laserinduced fluorescence (CE-LIF) on an Applied Biosystems 3730xl DNA Analyzer (Life Technologies, Carlsbad, CA, USA). Peaks were identified by co-migration with known standards and quantified based on peak area using quantitation standards analyzed in parallel. Oligosaccharides $\mathrm{Xyl}, \mathrm{Xyl}_{2}$, GlcA Xyl , and MeGlcA Xyl 4 were used to calculate the degree of xylan branching and the proportion of GlcA methylation, as described previously with the 
polysaccharide analysis using the carbohydrate gel electrophoresis technique [69].

\section{Saccharification assays}

The protocol for saccharification of senesced Arabidopsis inflorescences was as follows. Aliquots of $10 \mathrm{mg}$ of dry 2 - $\mathrm{mm}$ stem segments were used. The biomass was pretreated with $1 \mathrm{ml}$ of $1 \mathrm{~N} \mathrm{HCl}$ at $80^{\circ} \mathrm{C}$ for $2 \mathrm{~h}$, while shaking $(850 \mathrm{rpm})$. The acid extract was removed and the pretreated material was washed three times with $1 \mathrm{ml}$ water to obtain neutral $\mathrm{pH}$. Subsequently, the material was incubated with $1 \mathrm{ml} 70 \%(\mathrm{v} / \mathrm{v})$ ethanol overnight at $55^{\circ} \mathrm{C}$. The remaining biomass was washed three times with $1 \mathrm{ml} 70 \%(\mathrm{v} / \mathrm{v})$ ethanol, once with $1 \mathrm{ml}$ acetone, and dried under vacuum for $45 \mathrm{~min}$. For the saccharifications without pretreatment, $10 \mathrm{mg}$ aliquots of dry stem segments were immediately incubated with $1 \mathrm{ml} \mathrm{70 \%} \mathrm{(v/v)} \mathrm{ethanol} \mathrm{overnight} \mathrm{at} 55^{\circ} \mathrm{C}$. The extracted material was washed three times with $1 \mathrm{ml} 70 \%(\mathrm{v} / \mathrm{v})$ ethanol, once with $1 \mathrm{ml}$ acetone, dried under vacuum for $45 \mathrm{~min}$, and weighed. As this overnight ethanol extraction was an alternative procedure for cell wall preparation, the percentage of CWR in dry matter, specific for saccharification, could be calculated based on the weights before and after overnight ethanol extraction. As inclusion of the acid pretreatment prior to the overnight ethanol extraction removed some cell wall components, weighing the material after acid pretreatment and ethanol extraction overnight underestimated the amount of CWR. Therefore, the CWR data from the untreated samples were taken to calculate the glucose release with acid pretreatment per CWR.

The ethanol-extracted residue, after acid pretreatment or no pretreatment, was dissolved in $1 \mathrm{ml}$ acetic acid buffer solution $(\mathrm{pH} 4.8)$ and incubated at $50^{\circ} \mathrm{C}$. The enzyme mix added to the dissolved material contained cellulase from Trichoderma reseei ATCC 26921 and $\beta$-glucosidase (Novozyme, Bagsvaerd, Denmark) in a 5:3 ratio. Both enzymes were first desalted over an EconoPac 10DG column (Bio-Rad, Hercules, CA, USA), stacked with Bio-gel ${ }^{\circ}$ P-6DG gel (Bio-Rad) according to the manufacturer's guidelines. The desalted $\beta$-glucosidase was 350 -fold diluted prior to mixing with desalted cellulase. The enzyme mix was further diluted 10-fold and the activity of the diluted enzyme mix was measured with a filter paper assay [70]. To each biological sample, dissolved in acetic acid buffer ( $\mathrm{pH} 4.8$ ), the enzyme mix with an activity of 0.06 filter paper units was added. After a short spinning to remove droplets from the lid of the reaction tubes, $20 \mu \mathrm{l}$ aliquots of the supernatant were taken after $48 \mathrm{~h}$ of incubation at $50^{\circ} \mathrm{C}$ and 30 -fold diluted with acetic acid buffer ( $\mathrm{pH}$ 4.8). The concentration of glucose in these diluted samples was measured indirectly with a spectrophotometric color reaction (glucose oxidase-peroxidase; GOD-POD). A $100 \mathrm{ml}$ aliquot of the reaction mix from this color reaction contained $50 \mathrm{mg}$ 2,2'-azino-bis(3-ethylbenzthiazoline-6-sulfonic acid), $44.83 \mathrm{mg}$ GOD (Sigma-Aldrich, St. Louis, MO, USA), and $173 \mu \mathrm{l}$ of $4 \%$ (w/v) POD (Roche Diagnostics, Brussels, Belgium) in acetic acid buffer ( $\mathrm{pH} 4.5$ ). To measure the glucose concentration, $50 \mu \mathrm{l}$ of the diluted samples was added to $150 \mu \mathrm{l}$ GOD-POD solution and incubated for $30 \mathrm{~min}$ at $37^{\circ} \mathrm{C}$. The absorbance was measured spectrophotometrically at a wavelength of $405 \mathrm{~nm}$. The concentration in the original sample was calculated with a standard curve based on known D-glucose concentrations (Sigma-Aldrich).

\section{Descriptive statistics and significance tests}

All statistical analyses were performed with $\mathrm{SAS}^{\bullet} 9.2$ (SAS Institute Inc., 2008, Cary, North Carolina). Mixed model analysis was performed for each variable to test whether there was a significant line effect. Tray was put as a random effect in the model. The significance of the tray effect was assessed with a likelihood ratio test, using a mixture distribution of $\chi_{1}^{2}$ and $\chi_{0}^{2}$. When model assumptions were not met, box-cox powertransformations were applied to ensure the validity of the model. All variables were $\geq 0$. To variables that also contained values between 0 and 1 , the value 1 was added prior to transformation. Osborne [71] pointed out that for some transformations numbers between 0 and 1 are treated differently than numbers above 1 . In cases where no suitable powertransformation was possible, the nonparametric Friedman test was used. The applied transformations were as follows:

$$
\begin{aligned}
& \mathrm{H}=\text { square root of }(\mathrm{H}+1) ; \\
& \text { bis- } \beta-\mathrm{O}-4-\mathrm{FA}=(\text { bis- } \beta-\mathrm{O}-4-\mathrm{FA}+1)^{0.2} \\
& \beta-\mathrm{O}-4-\mathrm{FA}=\log _{\mathrm{e}}(\beta-\mathrm{O}-4-\mathrm{FA}+1) ; \\
& \mathrm{G} \text { aldehyde }=1 /(\mathrm{Gald}+1) ; \\
& \mathrm{S} \text { aldehyde }=1 /(\text { Sald }+1) ; \\
& \text { glucose }=1 / \text { square root }(\text { glucose }) ; \\
& \text { galactose }=\log _{\mathrm{e}} \text { (galactose) }
\end{aligned}
$$

A nonparametric analysis was applied to $\% \mathrm{H}, \% \mathrm{G}, \%$ S. Post-hoc Dunnett's tests (2-sided) were performed to test for significant differences between a particular line and wild-type. Differences with a Dunnett adjusted $p$-values $<0.01$ were considered significant. Differences are reported on their original scale, however the null hypotheses are valid on the transformed scale only. For the nonparametric test approximations to the rank-sum multiple comparisons were obtained.

Saccharification yield (mg glucose/mg CWR) was measured at different timepoints. A repeated measurements analysis was performed using a linear spline model with knots at timepoints $3 \mathrm{~h}, 8 \mathrm{~h}$ and $24 \mathrm{~h}$ based on the line 
plots. Several covariance structures were modelled. The model with the lowest AIC value was the model with an unstructured covariance. Tray was also included in the model as a random effect. The significance of the tray effect was assessed with a likelihood ratio test, using a mixture distribution of $\chi_{1}^{2}$ and $\chi_{0}^{2}$. The full model was:

Saccharification yield $=$ intercept+tray+line+time+time* line+time3+time3"line+time8+time8*line+time24+ time24*line.

One-sided post-hoc Dunnett's tests were performed at $48 \mathrm{~h}$ to test for significant increases in saccharification yield in a particular line compared to wild-type. Separate analyses were performed for the experiments with and without pretreatment.

\section{Statistical modeling of saccharification yield}

To understand which factors had the most significant influence, the saccharification yield in $\mathrm{mg}$ per $\mathrm{mg}$ dry weight at $48 \mathrm{~h}$ was modeled separately for the analysis with and without pretreatment by means of multiple linear regression. Data from the two $c c r 1$ and the $c 4 h-2$ mutants were not taken into account. The factors that were considered to influence the glucose release were lignin (mg), S/G, ferulic acid (bis- $\beta$-O-4-FA, $\mu \mathrm{mol}$ ), the three most abundant sugars (arabinose $(\mu \mathrm{g})$, galactose $(\mu \mathrm{g})$, and xylose $(\mu \mathrm{g}))$, cellulose $(\mathrm{mg})$, and matrix polysaccharides $(\mathrm{mg})$. All factors were expressed on a mg dry weight basis. In a first step, all correlations between the different independent variables were investigated to avoid multicollinearity. As the correlation between arabinose and galactose $(\mathrm{r}=0.94, p<.0001)$ was very high, arabinose was eliminated from the model. Multicollinearity was monitored with the variance inflation factor (VIF) of which the square root indicates how much larger the standard error is compared with what it would be if the variables were uncorrelated with the other independent variables in the equation. Models were built by manual backward selection with removal of one severe outlier. The $\mathrm{R}^{2}$ of the final model for the saccharification yield was 0.70 and 0.71 without and with pretreatment, respectively. The effect of pretreatment was also modeled with the same covariates; the $\mathrm{R}^{2}$ of the final model for this pretreatment effect was 0.58 .

\section{Additional files}

Additional file 1: Saccharification yields for the 20 mutants $(n=8)$ and wild-type $(n=16)( \pm S D)$ without and with acid pretreatment. Saccharification yields are expressed as percentage CWR. Increases and decreases compared to the wild-type are indicated in bold and italics, respectively. ${ }^{*} 0.001<p<0.01 ;{ }^{* *} p<0.001$ (Dunnett-Hsu adjusted $t$-test).
Additional file 2: Scatterplots containing data from the wild-type and all 20 mutants, except $c 4 h-2, c c r 1-3$, and $c c r 1-6$, illustrating that lignin reduction was compensated for by matrix polysaccharides rather than by cellulose (left column). The distinction between the different mutants and the wild-type is visualized by different colors. Scatterplots (middle and right columns) illustrate the relations between saccharification without and with acid pretreatment, respectively, and the different cell wall polymers (lignin, cellulose, and matrix polysaccharides). The Pearson correlation coefficient and its corresponding $p$-value are given in the upper left corner of each scatterplot.

Additional file 3: Pearson correlation matrix between phenotypic traits, cell wall polymers, and saccharification. The data of the wildtype and all mutants, except $c 4 h-2, c c r 1-3$, and $c c r 1-6$, were used to build the correlation matrix (Tables 1 to 4 and Additional file 1). The top half gives the $p$-values, the bottom half the Pearson correlation coefficients. Orange: Pearson correlation coefficient ( $r$ ) (and their corresponding $p$-values) $>0.7$; blue: $0.6<r<0.7$; green: $0.5<r<0.6$. A correlation coefficient of 0.7 indicates a strong linear relation, of $0.6<r<0.7$, a medium strong relation, and of $0.5<r<0.6$, a weak linear relation. Sacch 0 : saccharification yield without pretreatment; sacch 1: saccharification yield with acid pretreatment; conversion 0: cellulose conversion without pretreatment; conversion 1: cellulose conversion with acid pretreatment.

Additional file 4: Data used to build the models for saccharification yield without and with acid pretreatment and pretreatment effect. Saccharification yield without pretreatment (sacch0), with pretreatment (sacch1), lignin, cellulose, and matrix polysaccharides are expressed as mg per mg dry weight. Ferulic acid is expressed as $\mu \mathrm{mol}$ per mg dry weight. Arabinose, xylose, and galactose are expressed as $\mu \mathrm{g} \mathrm{mg}^{-1}$ dry weight.

Additional file 5: Matrix polysaccharide composition for the $\mathbf{2 0}$ lignin mutants $(n=8)$ and wild-type $(n=16)( \pm S D)$. The absolute amounts of the different sugars are expressed as $\mu \mathrm{g} \mathrm{mg}^{-1}$ dry weight. These absolute values for arabinose, xylose, and galactose were used to build the saccharification models. Increases compared to the wild-type are indicated in bold. ${ }^{*} 0.001<p<0.01$; ${ }^{* *} p<0.001$ (Dunnett-Hsu adjusted $t$-test).

Additional file 6: Lignin composition for the 20 lignin mutants $(\mathrm{n}=$ 8) and wild-type $(\mathbf{n}=16)( \pm$ SD). The absolute amounts of the different lignin monomers detected by thioacidolysis are expressed as $\mu \mathrm{mol} \mathrm{g} \mathrm{g}^{-1}$ $\mathrm{AcBr}$ lignin. Increases and decreases compared to the wild-type are indicated in bold and italics, respectively. ${ }^{*} 0.001<p<0.01$; ${ }^{* *} p<0.001$ (Dunnett-Hsu adjusted $t$-test).

Additional file 7: List of specific prominent ions used to extract the ion-specific chromatograms and quantify the different lignin units, released during thioacidolysis, in the $\mathbf{2 0}$ mutants and the wild-type. Target ions and qualifiers are $\mathrm{m} / \mathrm{z}$ values.

\section{Abbreviations}

4CL: 4-coumarate:CoA ligase; 5-OH-G: 5-hydroxyguaiacyl; AcBr: Acetyl Bromide; AIR: Alcohol-insoluble residue; $\mathrm{C} 3 \mathrm{H}$ : p-coumarate 3-hydroxylase; C4H: Cinnamate 4-hydroxylase; CAD: Cinnamyl alcohol dehydrogenase; CCOAOMT: caffeoyl-COA O-methyltransferase; CESA: Cellulose synthase; COMT: Caffeic acid O-methyltransferase; CCR: Cinnamoyl-CoA reductase; CWR: Cell wall residue; DASH: DNA sequencer Assisted Saccharide analysis in High throughput; F5H: Ferulate 5-hydroxylase; FA: Ferulic acid; G: Guaiacyl; GlcA: Glucuronic acid; GOD: Glucose oxidase; H: p-hydroxyphenyl; HCT: p-hydroxycinnamoyl-CoA:quinate shikimate $p$-hydroxycinnamoyltransferase; PAL: Phenylalanine ammonia lyase; POD: Peroxidase; S: Syringyl; TFA: Trifluoroacetic acid; TMS: Trimethylsilyl; VIF: Variance inflation factor.

\section{Competing interests}

The authors declare that they have no competing interests.

\section{Authors' contributions}

RVA and WB designed this study. RVA grew plants, carried out phenotypic analyses, cell wall characterizations, and saccharification assays. VS built the saccharification models and performed statistical analysis. JM performed DASH. PD helped interpreting the DASH data. RVA, RV, and WB wrote the manuscript. All authors read and approved the final manuscript. 


\section{Acknowledgements}

The authors would like to thank Xiaofei Li for help in performing DASH analyses and Martine De Cock for help in formatting the manuscript. This work was supported by grants from the Multidisciplinary Research Partnership "Biotechnology for a sustainable economy" (no. 01MRB510W) of Ghent University, the European Commission through the Directorate General Research within the 7th Framework Program (FP7/2007-2013) under grant agreement no. 211982 (RENEWALL), and the Biotechnology and Biological Sciences Research Council (BBSRC) Sustainable Bioenergy Centre Cell Wall Sugars Programme (Grant BB/G016240/1). RVA is indebted to the Agency for Innovation by Science and Technology (IWT) for a predoctoral fellowship.

\section{Author details}

'Department of Plant Systems Biology, VIB, Technologiepark 927, Gent 9052, Belgium. ${ }^{2}$ Department of Plant Biotechnology and Bioinformatics, Ghent University, Gent 9052, Belgium. ${ }^{3}$ Department of Biochemistry, Cambridge University, Cambridge CB2 1QW, United Kingdom.

Received: 27 December 2012 Accepted: 26 March 2013

Published: 26 April 2013

\section{References}

1. Hisano H, Nandakumar R, Wang Z-Y: Genetic modification of lignin biosynthesis for improved biofuel production. In Vitro Cell Dev Biol-Plant 2009, 45:306-313.

2. Yuan JS, Tiller KH, Al-Ahmad H, Stewart NR, Stewart NC Jr: Plants to power: bioenergy to fuel the future. Trends Plant Sci 2008, 13:421-429.

3. Chen F, Dixon RA: Lignin modification improves fermentable sugar yields for biofuel production. Nat Biotechnol 2007, 25:759-761.

4. Endler A, Persson S: Cellulose synthases and synthesis in Arabidopsis. Mol Plant 2011, 4:199-211.

5. Gírio FM, Fonseca C, Carvalheiro F, Duarte LC, Marques S, Bogel-kukasik R: Hemicelluloses for fuel ethanol: a review. Bioresour Technol 2010, 101:4775-4800.

6. Scheller HV, Ulvskov P: Hemicelluloses. Annu Rev Plant Biol 2010, 61:263-289.

7. Boerjan W, Ralph J, Baucher M: Lignin biosynthesis. Annu Rev Plant Biol 2003, 54:519-546.

8. Vanholme R, Demedts B, Morreel K, Ralph J, Boerjan W: Lignin biosynthesis and structure. Plant Physiol 2010, 153:895-905.

9. Himmel ME, Ding S-Y, Johnson DK, Adney WS, Nimlos MR, Brady JW, Foust TD: Biomass recalcitrance: engineering plants and enzymes for biofuels production. Science 2007, 315:804-807.

10. Cook CM, Daudi A, Millar DJ, Bindschedler LV, Khan S, Bolwell GP, Devoto A: Transcriptional changes related to secondary wall formation in xylem of transgenic lines of tobacco altered for lignin or xylan content which show improved saccharification. Phytochemistry 2012, 74:79-89.

11. Fornalé S, Capellades M, Encina A, Wang K, Irar S, Lapierre C, Ruel K, Joseleau J-P, Berenguer J, Puigdomènech P, Rigau J, Caparrós-Ruiz D: Altered lignin biosynthesis improves cellulosic bioethanol production in transgenic maize plants down-regulated for cinnamyl alcohol dehydrogenases. Mol Plant 2012, 5:817-830

12. Xu B, Escamilla-Treviño LL, Sathitsuksanoh N, Shen Z, Shen H, Zhang Y-HP, Dixon RA, Zhao B: Silencing of 4-coumarate:coenzyme A ligase in switchgrass leads to reduced lignin content and improved fermentable sugar yields for biofuel production. New Phytol 2011, 192:611-625.

13. Fu C, Xiao X, Xi Y, Ge Y, Chen F, Bouton J, Dixon RA, Wang Z-Y: Downregulation of cinnamyl alcohol dehydrogenase (CAD) leads to improved saccharification efficiency in switchgrass. BioEnergy Res 2011, 4:153-164.

14. Fu C, Mielenz JR, Xiao X, Ge Y, Hamilton CY, Rodriguez M Jr, Chen F, Foston M, Ragauskas A, Bouton J, Dixon RA, Wang Z-Y: Genetic manipulation of lignin reduces recalcitrance and improves ethanol production from switchgrass. Proc Natl Acad Sci USA 2011, 108:3803-3808.

15. Jung JH, Fouad WM, Vermerris W, Gallo M, Altpeter F: RNAi suppression of lignin biosynthesis in sugarcane reduces recalcitrance for biofuel production from lignocellulosic biomass. Plant Biotechnol J 2012, 10:1067-1076

16. Dien BS, Sarath G, Pedersen JF, Sattler SE, Chen H, Funnell-Harris DL, Nichols NN, Cotta MA: Improved sugar conversion and ethanol yield for forage sorghum (Sorghum bicolor L. Moench) lines with reduced lignin contents. BioEnergy Res 2009, 2:153-164.

17. Bouvier d'Yvoire M, Bouchabke-Coussa O, Voorend W, Antelme S, Cézard L, Legée F, Lebris P, Legay S, Whitehead C, McQueen-Mason SJ, Gomez LD, Jouanin L, Lapierre C, Sibout R: Disruspting the cinnamyl alcohol dehydrogenase 1 gene (BdCAD1) leads to altered lignification and improved saccharification in Brachypodium distachyon. Plant J 2013, 73:496-508

18. Vanholme R, Van Acker R, Boerjan W: Potential of Arabidopsis systems biology to advance the biofuel field. Trends Biotechnol 2010, 28:543-547.

19. Studer MH, DeMartini JD, Davis MF, Sykes RW, Davison B, Keller M, Tuskan GA, Wyman CE: Lignin content in natural Populus variants affects sugar release. Proc Natl Acad Sci USA 2011, 108:6300-6305.

20. Mansfield SD, Kang K-Y, Chapple C: Designed for deconstruction - poplar trees altered in cell wall lignification improve the efficacy of bioethanol production. New Phytol 2012, 194:91-101.

21. Min D, Li Q, Jameel H, Chiang V, Chang HM: The cellulase-mediated saccharification on wood derived from transgenic low-lignin lines of black cottonwood (Populus trichocarpa). Appl Biochem Biotechnol 2012, 168:947-955.

22. Papa G, Varanasi P, Sun L, Cheng G, Stavila V, Holmes B, Simmons BA, Adani $F$, Singh S: Exploring the effect of different plant lignin content and composition on ionic liquid pretreatment efficiency and enzymatic saccharification of Eucalyptus globulus L. mutants. Bioresour Technol 2012 117:352-359.

23. Li X, Ximenes E, Kim Y, Slininger M, Meilan R, Ladisch M, Chapple C: Lignin monomer composition affects Arabidopsis cell-wall degradability after liquid hot water pretreatment. Biotechnol Biofuels 2010, 3:27.

24. Dien BS, Miller DJ, Hector RE, Dixon RA, Chen F, McCaslin M, Reisen P, Sarath G, Cotta MA: Enhancing alfalfa conversion efficiencies for sugar recovery and ethanol production by altering lignin composition. Bioresour Technol 2011, 102:6479-6486.

25. Harris D, Stork J, Debolt S: Genetic modification in cellulose-synthase reduces crystallinity and improves biochemical conversion to fermentable sugar. GCB Bioenergy 2009, 1:51-61.

26. Xu N, Zhang W, Ren S, Liu F, Zhao C, Liao H, Xu Z, Huang J, Li Q, Tu Y, Yu B, Wang Y, Jiang J, Qin J, Peng L: Hemicelluloses negatively affect lignocellulose crystallinity for high biomass digestibility under $\mathrm{NaOH}$ and $\mathrm{H}_{2} \mathrm{SO}_{4}$ pretreatments in Miscanthus. Biotechnol Biofuels 2012, 5:58.

27. Lee C, Teng Q, Huang W, Zhong R, Ye Z-H: Down-regulation of PoGT47C expression in poplar results in a reduced glucuronoxylan content and an increased wood digestibility by cellulase. Plant Cell Physiol 2009, 50:1075-1089.

28. Mortimer JC, Miles GP, Brown DM, Zhang Z, Segura MP, Weimar T, Yu X, Seffen KA, Stephens E, Turner SR, Dupree P: Absence of branches from xylan in Arabidopsis gux mutants reveals potential for simplification of lignocellulosic biomass. Proc Natl Acad Sci USA 2010, 107:17409-17414.

29. Hu W-J, Harding SA, Lung J, Popko JL, Ralph J, Stokke DD, Tsai C-J, Chiang VL: Repression of lignin biosynthesis promotes cellulose accumulation and growth in transgenic trees. Nat Biotechnol 1999, 17:808-812.

30. Li L, Zhou Y, Cheng X, Sun J, Marita JM, Ralph J, Chiang VL: Combinatorial modification of multiple lignin traits in trees through multigene cotransformation. Proc Natl Acad Sci USA 2003, 100:4939-4944.

31. Jouanin L, Goujon T, de Nadaï V, Martin M-T, Mila I, Vallet C, Pollet B, Yoshinaga A, Chabbert B, Petit-Conil M, Lapierre C: Lignification in transgenic poplars with extremely reduced caffeic acid $O$ methyltransferase activity. Plant Physiol 2000, 123:1363-1373.

32. Vanholme R, Storme V, Vanholme B, Sundin L, Christensen JH, Goeminne G, Halpin C, Rohde A, Morreel K, Boerjan W: A systems biology view of responses to lignin biosynthesis perturbations in Arabidopsis. Plant Cell 2012, 24:3506-3529.

33. Schilmiller AL, Stout J, Weng J-K, Humphreys J, Ruegger MO, Chapple C: Mutations in the cinnamate 4-hydroxylase gene impact metabolism, growth and development in Arabidopsis. Plant J 2009, 60:771-782.

34. Mir Derikvand M, Sierra JB, Ruel K, Pollet B, Do C-T, Thévenin J, Buffard D, Jouanin $L$, Lapierre $C$ : Redirection of the phenylpropanoid pathway to feruloyl malate in Arabidopsis mutants deficient for cinnamoyl-CoA reductase 1. Planta 2008, 227:943-956.

35. Dence CW: Lignin determination. In Methods in Lignin Chemistry. 2nd edition. Edited by Lin SY, Dence CW. Berlin: Springer-Verlag (Wimmer R (Series Editor): Springer Series in Wood Science); 1992:33-61. 
36. Van Doorsselaere J, Baucher M, Chognot E, Chabbert B, Tollier M-T, PetitConil M, Leplé J-C, Pilate G, Cornu D, Monties B, Van Montagu M, Inzé D, Boerjan $W$, Jouanin $L$ : A novel lignin in poplar trees with a reduced caffeic acid/5-hydroxyferulic acid 0 -methyltransferase activity. Plant $J$ 1995, 8:855-864

37. Ralph J, Lapierre C, Marita JM, Kim H, Lu F, Hatfield RD, Ralph S, Chapple C, Franke R, Hemm MR, Van Doorsselaere J, Sederoff RR, O'Malley DM, Scott JT, MacKay JJ, Yahiaoui N, Boudet A-M, Pean M, Pilate G, Jouanin L, Boerjan W: Elucidation of new structures in lignins of CAD- and COMT-deficient plants by NMR. Phytochemistry 2001, 57:993-1003.

38. Morreel K, Ralph J, Lu F, Goeminne G, Busson R, Herdewijn P, Goeman JL, Van der Eycken J, Boerjan W, Messens E: Phenolic profiling of caffeic acid O-methyltransferase-deficient poplar reveals novel benzodioxane oligolignols. Plant Physiol 2004, 136:4023-4036.

39. Lu F, Marita JM, Lapierre C, Jouanin L, Morreel K, Boerjan W, Ralph J: Sequencing around 5-hydroxyconiferyl alcohol-derived units in caffeic acid O-methyltransferase-deficient poplar lignins. Plant Physiol 2010, 153:569-579.

40. Lapierre C, Pilate G, Pollet B, Mila I, Leplé J-C, Jouanin L, Kim H, Ralph J: Signatures of cinnamyl alcohol dehydrogenase deficiency in poplar lignins. Phytochemistry 2004, 65:313-321.

41. Kim H, Ralph J, Lu F, Pilate G, Leplé J-C, Pollet B, Lapierre C: Identification of the structure and origin of thioacidolysis marker compounds for cinnamyl alcohol dehydrogenase deficiency in angiosperms. J Biol Chem 2002, 277:47412-47419.

42. Sibout R, Eudes A, Pollet B, Goujon T, Mila I, Granier F, Séguin A, Lapierre C, Jouanin L: Expression pattern of two paralogs encoding cinnamyl alcohol dehydrogenases in Arabidopsis. Isolation and characterization of the corresponding mutants. Plant Physiol 2003, 132:848-860

43. Ralph J, Kim H, Lu F, Grabber JH, Leplé J-C, Berrio-Sierra J, Mir Derikvand M, Jouanin L, Boerjan W, Lapierre C: Identification of the structure and origin of a thioacidolysis marker compound for ferulic acid incorporation into angiosperm lignins (and an indicator for cinnamoyl CoA reductase deficiency). Plant J 2008, 53:368-379.

44. Leplé J-C, Dauwe R, Morreel K, Storme V, Lapierre C, Pollet B, Naumann A, Kang K-Y, Kim H, Ruel K, Lefèbvre A, Joseleau J-P, Grima-Pettenati J, De Rycke R, Andersson-Gunnerås S, Erban A, Fehrle I, Petit-Conil M, Kopka J, Polle A, Messens E, Sundberg B, Mansfield SD, Ralph J, Pilate G, Boerjan W: Downregulation of cinnamoyl-coenzyme A reductase in poplar: multiplelevel phenotyping reveals effects on cell wall polymer metabolism and structure. Plant Cell 2007, 19:3669-3691.

45. DuBois M, Gilles KA, Hamilton JK, Rebers PA, Smith F: Colorimetric method for determination of sugars and related substances. Anal Chem 1956, 28:350-356

46. Masuko T, Minami A, Iwasaki N, Majima T, Nishimura S-I, Lee YC Carbohydrate analysis by a phenol-sulfuric acid method in microplate format. Anal Biochem 2005, 339:69-72.

47. Pauly M, Keegstra K: Cell-wall carbohydrates and their modification as a resource for biofuels. Plant J 2008, 54:559-568.

48. Bonawitz ND, Chapple C: The genetics of lignin biosynthesis: connecting genotype to phenotype. Annu Rev Genet 2010, 44:337-363.

49. Ehlting J, Büttner D, Wang Q, Douglas CJ, Somssich IE, Kombrink E: Three 4-coumarate:coenzyme $A$ ligases in Arabidopsis thaliana represent two evolutionarily divergent classes in angiosperms. Plant J 1999, 19:9-20.

50. Huang J, Gu M, Lai Z, Fan B, Shi K, Zhou Y-H, Yu J-Q, Chen Z: Functional analysis of the Arabidopsis $P A L$ gene family in plant growth, development, and response to environmental stress. Plant Physiol 2010, 153:1526-1538.

51. Dixon RA, Chen F, Guo D, Parvathi K: The biosynthesis of monolignols: a "metabolic grid", or independent pathways to guaiacyl and syringyl units? Phytochemistry 2001, 57:1069-1084

52. Jones $L$, Ennos AR, Turner SR: Cloning and characterization of irregular xylem4 (irx4): a severely lignin-deficient mutant of Arabidopsis. Plant $J$ 2001, 26:205-216.

53. Prashant S, Srilakshmi Sunita M, Pramod S, Gupta RK, Anil Kumar S, Rao Karumanchi S, Rawal SK, Kavi Kishor PB: Down-regulation of Leucaena leucocephala cinnamoyl CoA reductase (LICCR) gene induces significant changes in phenotype, soluble phenolic pools and lignin in transgenic tobacco. Plant Cell Rep 2011, 30:2215-2231.

54. Meyer K, Shirley AM, Cusumano JC, Bell-Lelong DA, Chapple C: Lignin monomer composition is determined by the expression of a cytochrome
P450-dependent monooxygenase in Arabidopsis. Proc Natl Acad Sci USA 1998, 95:6619-6623.

55. Lee Y, Chen F, Gallego-Giraldo L, Dixon RA, Voit EO: Integrative analysis of transgenic alfalfa (Medicago sativa L.) suggests new metabolic control mechanisms for monolignol biosynthesis. PLoS Comput Biol 2011 7:e1002047.

56. Zhou R, Jackson L, Shadle G, Nakashima J, Temple S, Chen F, Dixon RA: Distinct cinnamoyl CoA reductases involved in parallel routes to lignin in Medicago truncatula. Proc Natl Acad Sci USA 2010, 107:17803-17808.

57. Vanholme R, Morreel K, Darrah C, Oyarce P, Grabber JH, Ralph J, Boerjan W: Metabolic engineering of novel lignin in biomass crops. New Phytol 2012, 196:978-1000

58. Rohde A, Morreel K, Ralph J, Goeminne G, Hostyn V, De Rycke R, Kushnir S, Van Doorsselaere J, Joseleau J-P, Vuylsteke M, Van Driessche G, Van Beeumen J, Messens E, Boerjan W: Molecular phenotyping of the pal1 and pal2 mutants of Arabidopsis thaliana reveals far-reaching consequences on phenylpropanoid, amino acid, and carbohydrate metabolism. Plant Cell 2004, 16:2749-2771.

59. Dauwe R, Morreel K, Goeminne G, Gielen B, Rohde A, Van Beeumen J, Ralph J, Boudet A-M, Kopka J, Rochange SF, Halpin C, Messens E, Boerjan W: Molecular phenotyping of lignin-modified tobacco reveals associated changes in cell-wall metabolism, primary metabolism, stress metabolism and photorespiration. Plant J 2007, 52:263-285.

60. Shi C, Koch G, Ouzunova M, Wenzel G, Zein I, Lübberstedt T: Comparison of maize brown-midrib isogenic lines by cellular UVmicrospectrophotometry and comparative transcript profiling. Plant $\mathrm{Mol}$ Biol 2006, 62:697-714.

61. Gallego-Giraldo L, Escamilla-Trevino L, Jackson LA, Dixon RA: Salicylic acid mediates the reduced growth of lignin down-regulated plants. Proc Natl Acad Sci USA 2011, 108:20814-20819.

62. Laskar DD, Jourdes M, Patten AM, Helms GL, Davin LB, Lewis NG: The Arabidopsis cinnamoyl CoA reductase irx4 mutant has a delayed but coherent (normal) program of lignification. Plant J 2006, 48:674-686.

63. Stackpole DJ, Vaillancourt RE, Alves A, Rodrigues J, Potts BM: Genetic variation in the chemical components of Eucalyptus globulus wood. G3 Genes|Genomes|Genet 2011, 1:151-159.

64. Chang XF, Chandra R, Berleth T, Beatson RP: Rapid, microscale, acetyl bromide-based method for high-throughput determination of lignin content in Arabidopsis thaliana. J Agric Food Chem 2008, 56:6825-6834

65. Robinson AR, Mansfield SD: Rapid analysis of poplar lignin monomer composition by a streamlined thioacidolysis procedure and near-infrared reflectance-based prediction modeling. Plant J 2009, 58:706-714

66. Yue F, Lu F, Sun R-C, Ralph J: Syntheses of lignin-derived thioacidolysis monomers and their uses as quantitation standards. J Agric Food Chem 2012, 60:922-928.

67. Foster CE, Martin TM, Pauly M: Comprehensive compositional analysis of plant cell walls (lignocellulosic biomass). Part II: Carbohydrates. J Vis Exp 2010, 37:e1837.

68. Fox A, Black GE, Fox K, Rostovtseva S: Determination of carbohydrate profiles of Bacillus anthracis and Bacillus cereus including identification of O-methyl methylpentoses by using gas chromatography-mass spectrometry. J Clin Microbiol 1993, 31:887-894.

69. Brown DM, Goubet F, Wong WW, Goodacre R, Stephens E, Dupree P, Turne SR: Comparison of five xylan synthesis mutants reveals new insight into the mechanisms of xylan synthesis. Plant J 2007, 52:1154-1168.

70. Xiao Z, Storms R, Tsang A: Microplate-based filter paper assay to measure total cellulase activity. Biotechnol Bioeng 2004, 88:832-837.

71. Osborne JW: Improving your data transformations: applying the Box-Cox transformation. Practical Assess Res Eval 2010, 15

doi:10.1186/1754-6834-6-46

Cite this article as: Van Acker et al:: Lignin biosynthesis perturbations affect secondary cell wall composition and saccharification yield in Arabidopsis thaliana. Biotechnology for Biofuels 2013 6:46. 